\title{
The Economics of Solicited and Unsolicited Credit Ratings*
}

\author{
Paolo Fulghieri $^{\dagger} \quad$ Günter Strobl ${ }^{\ddagger} \quad \mathrm{Han} \mathrm{Xia}^{\S}$
}

December 2012

\begin{abstract}
This paper develops a dynamic rational expectations model of the credit rating process, incorporating three critical elements of this industry: (i) the rating agencies' ability to misreport the issuer's credit quality, (ii) their ability to issue unsolicited ratings, and (iii) their reputational concerns. We analyze the incentives of credit rating agencies to issue unsolicited credit ratings and the effects of this practice on the agencies' rating strategies. We find that the issuance of unfavorable unsolicited credit ratings enables rating agencies to extract higher fees from issuers by credibly threatening to punish those that refuse to acquire a rating. Also, issuing unfavorable unsolicited ratings increases the rating agencies' reputation by demonstrating to investors that they resist the temptation to issue inflated ratings. In equilibrium, unsolicited credit ratings are lower than solicited ratings, because all favorable ratings are solicited; however, they do not have a downward bias. We show that, under certain conditions, a credit rating system that incorporates unsolicited ratings leads to more stringent rating standards.
\end{abstract}

*We thank Arnoud Boot, Erik Fasten, Adlai Fisher, Gergana Jostova, Koralai Kirabaeva, Praveen Kumar, Stefano Lovo, Uday Rajan, Francesco Sangiorgi, Chester Spatt, Jie Yang, as well as seminar participants at Arizona State University, Bocconi University, Boston University, Cheung Kong Graduate School of Business, Erasmus University Rotterdam, the European Central Bank, the FDIC, Frankfurt School of Finance \& Management, George Washington University, Georgia Institute of Technology, HEC Paris, Indiana University, IESE Business School, Luxembourg School of Finance, Rice University, Shanghai Advanced Institute of Finance, Texas A\&M University, University of Alberta, University of Amsterdam, University of Calgary, University of California at Davis, University of Cambridge, Universidad Carlos III de Madrid, University of Georgia, University of Houston, University of North Carolina, Universitat Pompeu Fabra, University of Texas at Dallas, University of Virginia, the 2010 FMA meetings, the 6th NYU Stern/NYFRB Conference on Financial Intermediation, the 21st Annual Conference on Financial Economics and Accounting, the 7th Annual Conference on Corporate Finance at the Washington University in St. Louis, the Conference on Credit Rating Agencies and the Certification Process at Humboldt University in Berlin, the 2011 UBC Winter Finance Conference, the 13th Annual Texas Finance Festival, the 3rd Financial Stability Conference at Tilburg University, the 2011 WFA meetings, the 2011 EFA meetings, and the 2012 AEA meetings for comments on an early draft.

${ }^{\dagger}$ Kenan-Flagler Business School, University of North Carolina at Chapel Hill, McColl Building, C.B. 3490, Chapel Hill, NC 27599-3490. Tel: +1 (919) 962-3202; Fax: +1 (919) 962-2068

${ }^{\ddagger}$ Frankfurt School of Finance \& Management, Sonnemannstrasse 9-11, 60314 Frankfurt, Germany. Tel: +49 (69) 154008-445; Fax: +49 (69) 154008-4445; Email: g.strobl@fs.de

$\S$ Jindal School of Management, University of Texas at Dallas, 800 W. Campbell Road, SM.31, Richardson, TX 15080. Tel: +1 (972) 883-6385; Fax: +1 (972) 883-5837; Email: Han.Xia@utdallas.edu 


\section{Introduction}

The role of credit rating agencies as information producers has attracted considerable attention in the last decade. Of particular concern to both investors and regulators is the incentive of credit rating agencies to inflate their ratings to please fee-paying issuers, questioning the effectiveness of reputation as a disciplining device. ${ }^{1}$

Among the most controversial aspects of the credit rating industry is the issuance of unsolicited ratings for corporate credit instruments. Unsolicited ratings are published by credit rating agencies "without the request of the issuer or its agent" (Standard \& Poor's, 2007). In contrast to solicited ratings, which are requested and paid for by issuers, the issuance of unsolicited ratings does not involve the payment of a rating fee. Unsolicited credit ratings have been widely used since the 1990s and account for a sizeable portion of the total number of credit ratings. ${ }^{2}$

Despite the prevalence of unsolicited credit ratings, the agencies' incentives to issue them are not well understood. In a speech given in 2005, then-Chief Economist of the U.S. Securities and Exchange Commission Chester Spatt argued that "from an incentive compatibility perspective, this [practice] would appear to weaken the incentive constraint that encourages a firm to pay for being rated; this suggests that it is puzzling that the rating services evaluate companies that do not pay for ratings" (Spatt, 2005). ${ }^{3}$ Credit rating agencies argue that

\footnotetext{
${ }^{1}$ For example, credit rating agencies have been criticized for being slow in recognizing the deteriorating financial conditions of Enron and WorldCom in the early 2000s. More recently, they have been accused of bearing some responsibility for the financial crisis of 2007-2009 by having been too lax in the ratings of some structured financial products (e.g., White, 2010). These events have prompted regulatory responses through the Credit Rating Agency Reform Act of 2006 and, more recently, certain sections of the Dodd-Frank Wall Street Reform and Consumer Protection Act of 2010.

${ }^{2}$ Focusing on international issuers that received a credit rating by Standard and Poor's during the period from 1998 to 2000, Poon (2003) reports that unsolicited ratings have been assigned to 323 out of 595 issuers (53\%). Using a more comprehensive data set of international issuers, Bannier, Behr, and Güttler (2010) find that unsolicited ratings account for between $20 \%$ and $30 \%$ of all ratings issued between 2000 and 2005 . For the U.S. market, Gan (2004) estimates that between 1994 and 1998 about $22 \%$ of all new issue ratings were unsolicited ratings. This estimate is based on rating fees paid by the issuers; the exact number is not known, since prior to 2004 rating agencies did typically not disclose whether a credit rating was solicited by the issuer or not. Furthermore, by directly looking at Standard and Poor's RatingsXpress data for the post-2004 period, we find that unsolicited ratings account for about 10\% of the ratings between 2004 and 2011.

${ }^{3}$ In addition, Chester Spatt suggested that "the most natural way to resolve the puzzle [...] would be if the
} 
unsolicited ratings should be seen as a service to "meet the needs of the market for broader ratings coverage" (Standard \& Poor's, 2007). Issuers, on the other hand, have expressed concern that these ratings - which they sometimes refer to as "hostile ratings" - are used to punish firms that would otherwise not purchase ratings coverage. For example, Herbert Haas, a former chief financial officer of the German insurance company Hannover Re, recalls a conversation with a Moody's official in 1998 who told him that if Hannover paid for a rating, it "could have a positive impact" on the grade. ${ }^{4}$ This practice seems to be consistent with the empirical evidence showing that unsolicited ratings are, on average, lower than solicited ratings. ${ }^{5}$

In this paper, we develop a dynamic rational expectations model to address the question of why rating agencies issue unsolicited credit ratings and why these ratings are, on average, lower than solicited ratings. We analyze the implications of this practice for credit rating standards, rating fees, and social welfare. Our model incorporates three critical elements of the credit rating industry: (i) the rating agencies' ability to misreport the issuer's credit quality, (ii) their ability to issue unsolicited ratings, and (iii) their reputational concerns.

We focus on a monopolistic rating agency that interacts with a series of potential issuers that approach the credit market to finance their investment projects. ${ }^{6}$ Markets are characterized by asymmetric information in that the firms' true credit worthiness is private information

unsolicited ratings were not as favorable to the rated company as the paid or solicited ratings" so that "the systematic downward bias in unsolicited ratings [is a way to] 'punish' firms that would otherwise not purchase ratings."

${ }^{4}$ See The Washington Post from November 24, 2004. The article reports that within weeks after Hannover refused to pay for Moody's services, Moody's issued an unsolicited rating for Hannover, giving it a financial strength rating of "Aa2," one notch below that given by S\&P. Over the course of the following two years, Moody's lowered Hannover's debt rating first to "Aa3" and then to "A2." Meanwhile, Moody's kept trying to sell Hannover its rating services. In March 2003, after Hannover continued to refuse to pay for Moody's services, Moody's downgraded Hannover's debt by another three notches to junk status, sparking a 10\% drop in the insurer's stock price. The scale of this downgrade came as a surprise to industry analysts, especially since the two rating agencies Hannover paid for their services, S\&P and A.M. Best, continued to give Hannover high ratings. For a more detailed account of this incident, see Klein (2004); additional anecdotal evidence of this practice can be found in Monroe (1987) and Schultz (1993).

${ }^{5}$ See, e.g., Gan (2004), Poon and Firth (2005), Van Roy (2006), and Bannier, Behr, and Güttler (2010).

${ }^{6}$ While we deliberately ignore the effect of competition and the related issue of "ratings shopping" in our analysis, it is important to note that the credit rating industry is a very concentrated and partially segmented market where three providers (Standard and Poor's, Moody's, and Fitch) have a market share of over $90 \%$. 
to the issuers. The credit rating agency evaluates the issuers' credit quality, that is, their ability to repay investors. It makes these evaluations public by assigning credit ratings to issuers in return for a fee. Issuers agree to pay for these rating services only if they believe that their assigned rating substantially improves the terms at which they can raise capital. This creates an incentive for the rating agency to strategically issue inflated ratings in order to motivate issuers to pay for them. At the same time, investors cannot directly observe the agency's rating policy. Rather, they use the agency's past performance, as measured by the debt-repaying records of previously rated issuers, to assess the credibility of its ratings. The agency's credibility in the eyes of investors is summarized by its "reputation."

The credit rating agency faces a dynamic trade-off between selling inflated ratings to boost its short-term profit and truthfully revealing the firms' prospects to improve its longterm reputation. ${ }^{7}$ Issuing inflated ratings is costly to the rating agency in the long run, since it increases the likelihood that a highly rated issuer will not be able to repay its debt, thereby damaging the rating agency's reputation. This, in turn, lowers the credibility of the rating agency's reports, making them less valuable to issuers and thus reducing the fee that the rating agency can charge for them in the future. The rating agency's optimal strategy balances higher short-term fees from issuing more favorable reports against higher long-term fees from an improved reputation for high-quality reports. Thus, in our model reputational concerns act as a disciplining device by curbing the agency's incentive to inflate its ratings. This disciplining effect is, however, limited by the fact that, after a default, investors are not able to perfectly distinguish cases of "bad luck" from cases of "bad ratings" (that is, inflated ratings).

Our analysis shows that the adoption of unsolicited credit ratings increases the rating agency's short-term profit as well as its long-term profit. This result is driven by two reinforcing effects. First, the ability to issue unsolicited ratings enables the rating agency to

\footnotetext{
${ }^{7}$ As we will discuss in Section 2, we adopt the "adverse selection" approach to modeling reputation where, by assumption, players are uncertain about some key characteristic of other players (Mailath and Samuelson, 2006, chapter 15).
} 
charge higher fees for their solicited ratings. The reason is that the rating agency can use its ability to issue unfavorable unsolicited ratings as a credible "threat" that looms over issuers that refuse to pay for its rating services. This threat increases the value of favorable solicited ratings and, hence, the fee that issuers are willing to pay for them.

The credibility of this threat stems from the fact that, by releasing unfavorable unsolicited ratings, the rating agency can demonstrate to investors that it resists the temptation to issue inflated ratings in exchange for a higher fee, which improves its reputation. This second effect, in the form of a reputational benefit, gives the rating agency an incentive to release an unsolicited ratings in case an issuer refuses to solicit a rating. ${ }^{8}$ Note that this threat is only latent because, in equilibrium, high-quality issuers prefer to acquire favorable solicited ratings. Thus, in equilibrium, the credit rating agency issues unsolicited ratings along with solicited ratings. Since all favorable ratings are solicited, unsolicited credit ratings are lower than solicited ratings. However, they are not downward biased. Rather, they reflect the lower quality of issuers that do not solicit a rating.

The adoption of unsolicited credit ratings also has important welfare implications. We find that while rating agencies always benefit from such a policy - because of the higher fees that they can charge - society may not. In particular, we show that, for some parameter values, allowing rating agencies to issue unsolicited ratings leads to less stringent rating standards, thereby enabling more low-quality firms to finance negative NPV projects. This reduces social welfare and raises the cost of capital for high-quality borrowers. Such an outcome is obtained when the increase in rating fees associated with the adoption of unsolicited ratings is sufficiently large so that it outweighs the additional reputational benefit from truthfully revealing the firm's quality. When this increase in rating fees is small (which happens, for example, when the loss in market value due to an unfavorable unsolicited rating is low), we obtain the opposite result: the ability to issue unsolicited ratings leads to more stringent

\footnotetext{
${ }^{8}$ This reputational benefit associated with unsolicited ratings may also explain why credit rating agencies issue sovereign debt ratings for which they do not receive any direct compensation.
} 
rating standards, which prevents firms from raising funds for negative NPV investments and, hence, improves social welfare. These results suggest that the question of whether credit rating agencies should be allowed to issue unsolicited ratings and, thus, to earn higher fees has no unambiguous answer.

Finally, we find that credit rating standards are countercyclical: the rating agency is more likely to issue inflated ratings during periods of economic expansion than during recessions. This is true whether or not the rating agency is allowed to issue unsolicited ratings. Consistent with the evidence in Ashcraft, Goldsmith-Pinkham, and Vickery (2010) and He, Qian, and Strahan (2012), this result implies that credit rating agencies loosen their rating standards during periods of high economic growth, which leads to an increase in default rates of highly rated securities.

Our paper contributes to the growing literature on the role of credit rating agencies and the phenomenon of ratings inflation. Mathis, McAndrews, and Rochet (2009) examine the incentives of a credit rating agency to inflate its ratings in a dynamic model of endogenous reputation acquisition. They show that reputational concerns can generate cycles of confidence in which the rating agency builds up its reputation by truthfully revealing its information only to later take advantage of this reputation by issuing inflated ratings. In Bolton, Freixas, and Shapiro (2012), ratings inflation emerges from the presence of a sufficiently large number of naive investors who take ratings at face value. Opp, Opp, and Harris (2012) argue that ratings inflation may result from regulatory distortions when credit ratings are used for regulatory purposes such as bank capital requirements. Finally, Skreta and Veldkamp (2009) and Sangiorgi and Spatt (2011) focus on "ratings shopping" as an explanation for inflated ratings. While both papers assume that rating agencies truthfully disclose their information to investors, the ability of issuers to shop for favorable ratings introduces an upward bias. In Skreta and Veldkamp (2009), investors do not fully account for this bias, which allows issuers to exploit this winner's curse fallacy. In contrast, Sangiorgi and Spatt (2011) demonstrate that when investors are rational, shopping-induced ratings inflation does not have any ad- 
verse consequences. While these papers share some important features with ours, the main contribution of our paper is to explicitly address the effect of unsolicited ratings on the rating policy adopted by credit rating agencies and their impact on ratings inflation.

Our paper is also related to the broader literature on reputation as an incentive mechanism. This literature is enormous and we will not do it justice here. Firms have been shown to face reputational concerns in many aspects of their business, including repaying debt (Diamond, 1989), fighting new entrants (Kreps and Wilson, 1982; Milgrom and Roberts, 1982), not holding up suppliers (Banerjee and Duflo, 2000), meeting earnings targets (Fisher and Heinkel, 2008) and producing quality products (Cabral, 2000; Hörner, 2002). Reputation is also known to matter for underwriters (Chemmanur and Fulghieri, 1994a), banks (Chemmanur and Fulghieri, 1994b), and workers (Tadelis, 1999). For reputation to be interesting from an economist's viewpoint, the benefit of "cheating" (not repaying debt, for example) must be weighed against the cost of a lost reputation. These papers show that costs of reputation loss can be large enough to ensure "good behavior."

A number of empirical papers have shown that unsolicited ratings are significantly lower than solicited ratings, both in the U.S. market and outside the U.S. ${ }^{9}$ These studies explore the reasons for this difference based on two hypotheses. The "self-selection hypothesis" argues that high-quality issuers self-select into the solicited rating group, while low-quality issuers self-select into the unsolicited rating group. Under this hypothesis, unsolicited ratings are unbiased, and thus they are not unduly "punitive" to issuing firms. In contrast, the "punishment hypothesis" argues that lower unsolicited ratings are a punishment for issuers that do not pay for rating services and are therefore downward biased. Under this hypothesis, given the same rating level, an issuer whose rating is unsolicited should ex post perform better than one whose rating is solicited.

The findings of these papers provide conflicting evidence. On the one hand, using S\&P

\footnotetext{
${ }^{9}$ A partial list includes Poon (2003), Gan (2004), Poon and Firth (2005), Van Roy (2006), and Bannier, Behr, and Güttler (2010).
} 
bond ratings on the international market, Poon (2003) reports that issuers who chose not to obtain rating services from S\&P have weaker financial profiles, which is consistent with the "self-selection hypothesis." Gan (2004) finds no significant difference between the performance of issuers with solicited and unsolicited ratings. This result leads her to reject the "punishment hypothesis" in favor of the "self-selection hypothesis." On the other hand, Bannier, Behr, and Güttler (2010) cannot reject the "punishment hypothesis" for their sample.

Our paper suggests an alternative explanation for these findings. We show that while unsolicited ratings are lower, they are not necessarily downward biased. Rather, they reflect the lower quality of issuers, as suggested by the self-selection hypothesis. This does not mean, however, that rating agencies cannot use unfavorable unsolicited ratings as a threat in order to pressure issuers to pay higher fees for more favorable ratings. We show that the rating agency's ability to issue unfavorable unsolicited ratings to high-quality firms can act as a credible punishment even though it may not be carried out in equilibrium and, hence, may not be observed by investors. This happens because, in equilibrium, the rating agency optimally sets the fee that it charges for favorable solicited ratings at a level at which issuers prefer to purchase them rather than risk obtaining unfavorable unsolicited ratings.

The remainder of this paper is organized as follows. Section 2 introduces the model. Section 3 describes the equilibrium of the model and analyzes the optimal rating policy in a solicited-only rating system. Section 4 solves for the equilibrium strategies in a rating system that incorporates unsolicited ratings. Section 5 compares the rating agency's fees and rating standards under the two rating systems and derives implications for social welfare. Section 6 summarizes our contribution and concludes. All proofs are contained in the Appendix. 


\section{The Model}

We consider an economy endowed with three types of risk-neutral agents: firms (or "issuers"), a credit rating agency (CRA), and investors. ${ }^{10}$ The game has two periods, denoted by $t \in\{1,2\}$. The riskless rate is normalized to zero.

At the beginning of each period, a firm has access to an investment project with probability $\beta$ (the game tree is displayed in Figures 1 and 2). The project requires an initial investment of $I$ units of capital. Firms have no capital and therefore must raise funds from outside investors in perfectly competitive capital markets. If the project is undertaken, it yields an end-of-period payoff of $R>I$ if successful $(\omega=S)$ and a payoff of zero if it fails $(\omega=F)$, after which the firm is wound down and ceases to exist. The outcome of the project, that is whether the project succeeds or fails, is observable to outside investors. If a firm does not invest, the project vanishes and the firm becomes worthless. Firms that do not have a project in the first period may have a new opportunity to invest in a project in the second period, if they obtain one (which happens again with probability $\beta$ ). Absent a project, the firm has no financing needs and does not access the capital market.

Investment projects are of heterogeneous quality, where project quality is characterized by its success probability. A type- $G$ project (denoted by $\theta=G$ ) has a success probability of $q$, whereas a type- $B$ project $(\theta=B)$ has a success probability of zero. ${ }^{11}$ Investors believe ex ante that a fraction $\alpha$ of projects are "good" (i.e., of type $G$ ) and a fraction $1-\alpha$ are "bad" (i.e., of type $B$ ). We assume that, on average, firms have access to positive NPV projects, that is, $\alpha q R-I>0$. We use $\theta=N$ to denote a firm without a project.

\footnotetext{
${ }^{10}$ The organizational structure of the credit rating industry is not critical to our analysis. All we need is that the market for credit ratings is not perfectly competitive and that the CRA has some market power, so that in equilibrium the CRA can extract some of the surplus it generates. The presence of these rents makes reputation valuable, allowing it to serve as a disciplining device. This is a plausible scenario since in markets where reputation matters, a "good" reputation is acquired slowly over time and is necessarily in limited supply, making these markets inherently imperfectly competitive. In contrast, perfectly competitive markets are populated by anonymous players, and reputation building plays no role.

${ }^{11}$ We focus on the case where type- $B$ projects have zero success probability for expositional simplicity. It is straightforward, although a bit messier, to extend the analysis to the case where type- $B$ projects succeed with a positive probability of less than $q$.
} 
Financial markets are characterized by asymmetric information. While firm insiders know the quality of their own project, outside investors cannot tell a firm with a good project from a firm with a bad one. This creates a role for the CRA: by releasing a "credit rating," the CRA can reduce the information asymmetry between firms and investors and, possibly, allow firms to raise capital at better terms. We assume that the CRA is able to produce information that is valuable to investors. This may happen because the CRA has access to private information not available to investors and/or to a superior information production technology that allows the CRA to obtain better estimates of firms' default and recovery rates. This information production technology may be the outcome, for example, of the CRA's specialized knowledge in assessing a firm's credit risk.

The rating process is typically initiated by an issuer approaching a CRA to rate a particular debt issue (the "request"). The CRA then assembles a team of analysts to review pertinent information (the "pre-evaluation"). The analysts meet with the issuer's management team to discuss the information (the "management meeting"). Based on their evaluation, the analysts then make a rating recommendation to the rating committee. The rating committee reviews the proposed rating and votes on it (the "committee evaluation"). At this point, the CRA generally provides the issuer with a pre-publication rationale for its credit rating (the "notification"), which may be appealed by the issuer. Finally, the CRA publishes the rating (the "publication" ). ${ }^{12}$ In addition, while solicited credit ratings are clearly sponsored by the issuer (although they may be initiated by the CRA), unsolicited credit ratings may or may not involve the participation of the issuer in the rating process. ${ }^{13}$

In this spirit, we model the credit rating process as follows. At the beginning of each period, a firm that obtained a project decides whether or not to request a credit rating

\footnotetext{
${ }^{12}$ See Standard \& Poor's (2012) and Moody's (2012). A detailed description of the rating process can also be found in Langohr and Langohr (2008, chapter 4).

${ }^{13}$ For example, Moody's Policy for Designating Unsolicited Credit Ratings in the European Union (effective September 9, 2011) indicates that "solicitation may be evidenced by a request, rating application or contract, payment of fees or confirmation. Participation by the rated entity in the rating process alone does not render a rating solicited" (Moody's, 2011).
} 
from the CRA. If it requests a rating, the CRA learns the firm's type at no cost. ${ }^{14}$ If the firm does not request a rating, the CRA observes its project quality only with probability $\delta \in(0,1)$. With probability $1-\delta$ the CRA does not observe any signal, and the firm is pooled with firms that do not have an investment project. Thus, the quality of the CRA's information is higher for ratings that were requested by the firm than for those that were not. This assumption captures the notion that, when soliciting a rating, firms make their books available for inspection by the rating agency and hence disclose private information to the agency that is not available to other market participants. In contrast, unsolicited ratings are in many cases just based on public information (and on the CRA's information production technology). ${ }^{15}$

Based on its information, the CRA then proposes a credit rating $r$ to the firm. We assume that a credit rating can only be issued for a firm known to have an investment project. ${ }^{16}$ This is the case if the firm requested a rating (in which case the CRA learns the firm's project quality) or, in the case the firm did not request a rating, if the CRA has observed an informative signal about the firm (which happens with probability $\delta$ ). The credit rating can be either "high" $(r=H)$ or "low" $(r=L)$. The fee $\phi^{r}$ charged by the CRA for a rating $r$ is a fraction $\gamma \in(0,1]$ of the "surplus value" generated by the rating for the firm. This surplus value is the difference between the firm's (net) market value associated with the rating and

\footnotetext{
${ }^{14}$ Our main results also go through in a setting where the CRA can observe the signal at positive cost (as long as this cost is not too large). This is driven by the fact that, in equilibrium, the CRA is better off releasing a rating after acquiring information about the rated firm, rather than issuing a rating blindly and thus putting its reputation at risk, as long as the cost of information acquisition is not too high.

${ }^{15} \mathrm{We}$ adopt this information structure in order to model in a parsimonious way the feature that solicited credit ratings are based on better information than unsolicited ones. Our model could be extended by assuming that the signal observed by the CRA about the quality of the firm's project is noisier when the firm does not request a rating.

${ }^{16}$ This can be justified by the fact that, in reality, a credit rating is not just a "notch" on a certain grading scale, but a comprehensive report describing the firm's business activities, projected cash flows, risk factors, etc., that is, an assessment of the firm's investment opportunity set. This feature also models the observation that firms with a debt rating are only a relatively small group. For example, Faulkender and Petersen (2006) report that on average only $21 \%$ of public firms have a debt rating between 1986 and 2000; more recently, Avramov, Chordia, Jostova, and Philipov (2012) find that between 1985 and 2008 there are on average 1,931 rated firms out of a universe of approximately 5,000 firms covered by the Center for Research in Security Prices (CRSP).
} 
its market value without such a rating (which will depend on the CRA's equilibrium strategy when the firm refuses to acquire a rating). We assume that $\gamma$ is the same in both periods and is common knowledge. ${ }^{17}$ The prospective rating and the fee are privately proposed by the CRA to the issuing firm and are not observable to investors.

The firm can either accept the CRA's offer and pay the fee or decline the offer. We assume that firms make their decisions to maximize the market value of their shares (net of investment expenses and the rating fee). ${ }^{18}$ If the firm accepts the offer, the CRA collects the rating fee and publicizes the rating as a "solicited credit rating" $r \in\{H, L\}$ to investors. If the firm declines the offer, it does not pay the fee. The CRA can then choose to either issue an "unsolicited rating" $r \in\{h, \ell\}$ or not to issue a rating at all (denoted by $r=\emptyset$ ). ${ }^{19}$ Note that if the CRA decides to issue an unsolicited rating, it does not have to be the same as the one proposed to the firm.

Credit ratings are important to firms because they affect the terms at which they can raise capital from investors. Investors' valuation of a firm depends on the firm's credit rating as well as the credibility of the CRA which issued the rating. The latter is important because the CRA cannot commit to truthfully reveal its information about a firm's quality to investors. Rather, it may have an incentive to misreport its information, which is not directly observable to investors. Investors must therefore decide to what extent they should trust the CRA and its ratings, based on available information such as the CRA's past track record.

To capture these ideas in our model, we adopt the "adverse selection" approach to modeling reputations introduced by Kreps and Wilson (1982) and Milgrom and Roberts (1982). In

\footnotetext{
${ }^{17}$ This compensation rule is adopted to capture, in the simplest way possible, the dependency of the CRA's fee on the incremental value of its ratings. The fraction $\gamma$ can be thought of as representing the CRA's bargaining power, exogenous to the model, while bargaining with the firm. Alternatively, it may depend on the competitive pressure among CRAs (not modeled here). In a similar vein, Opp, Opp, and Harris (2012) suggest that the outside options of firms are affected by competitive pressure.

${ }^{18}$ The assumption that firms only care about their short-term market value is not critical to our analysis. Introducing a component based on a firm's long-term profit would not affect our results qualitatively as long as the short-term component is sufficiently important.

${ }^{19}$ We use lower-case letters for unsolicited ratings to differentiate them from solicited ratings. This reflects the current practice of rating agencies to identify unsolicited ratings as such.
} 
particular, we assume that there are two types of CRA: ethical ones (denoted by $\tau=e$ ) and opportunistic ones $(\tau=o)$. An ethical CRA is "committed" to truthfully reveal its information about a firm whether a rating is solicited or not. It always offers to issue an $H$-rating for firms known to be good and an $L$-rating for firms known to be bad. An opportunistic CRA, on the other hand, chooses a credit rating policy that maximizes its expected profit over the two periods. Investors do not observe the CRA's type and believe that, at the beginning of period 1 , the CRA is of the ethical type with probability $\mu_{1}$ (and is of the opportunistic type with probability $\left.1-\mu_{1}\right)$. As investors get more information about the credit ratings released by the CRA and observe its performance over time, they update their beliefs about the CRA's type (as discussed in the next section). While the investors' updating process is driven by the fact that, in each period, there is a single firm that can obtain a credit rating, we want to emphasize that this assumption is not crucial to our results. The presence of multiple rated firms would allow investors to draw sharper inferences about the CRA's type (e.g., Opp, Opp, and Harris, 2012), but would not alter our basic conclusions as long as investors cannot perfectly infer the CRA's type from the observed ratings and default rates. ${ }^{20}$

\section{The Solicited-Only Credit Rating System}

In this section, we solve for the equilibrium in a rating system with solicited ratings only. In this case, the CRA's rating policy in period $t$ is fully characterized by the vector $\left\{p_{t}^{G}, p_{t}^{B}\right\}$, where $p_{t}^{\theta}$ denotes the probability that an $H$-rating is offered to a firm of type $\theta \in\{G, B\}$.

Absent the option of issuing unsolicited ratings, firms that decline to purchase a rating remain unrated. As we will show below, this applies (in equilibrium) to all firms that are offered an $L$-rating by the CRA. These firms are better off not acquiring a rating, since an $L$-rating would reveal that they are of the bad type and, hence, that their value is lower

\footnotetext{
${ }^{20}$ This would be the case, for example, if the fraction of good projects were not constant over time (as is assumed here), but rather followed a stochastic process whose realizations were unknown to investors.
} 
than the value of a firm without a project. ${ }^{21}$ Thus, for expositional simplicity, our discussion below focuses only on the case where the CRA either issues an $H$-rating or the firm remains unrated. We let $\phi_{t}$ denote the fee that the CRA charges for an $H$-rating.

We also conjecture (and verify below) that in equilibrium all firms with an investment project request a rating, thereby revealing their type to the CRA. Further, the CRA offers a favorable $H$-rating to all type- $G$ firms. Thus, while "ratings inflation" (that is, type- $B$ firms receiving an $H$-rating) will be part of our equilibrium, "ratings deflation" (type- $G$ firms receiving an $L$-rating) will not. We therefore simplify our notation by setting $p_{t}^{G}=1$, and by letting $p_{t}$ denote the probability that an $H$-rating is offered to a firm known to be of type $B$.

We begin our analysis by discussing how the CRA's rating policy affects its reputation. Since an ethical CRA always assigns an $H$-rating ( $L$-rating) to a type- $G$ (type- $B$ ) firm, whereas an opportunistic CRA may prefer to follow a different rating policy, the observation of the CRA issuing a credit rating and the subsequent performance of the rated firm is informative about the CRA's type. Accordingly, investors update their beliefs about the CRA's type twice in each period. The first updating takes place after the CRA releases a rating; the second updating occurs when investors observe the outcome (i.e., success or failure) of the firm's investment project (if an investment has been made).

Let $\mu_{t}$ denote the CRA's reputation at the beginning of period $t \in\{1,2\}$. The first round of updating occurs after the release of a rating $r_{t} \in\{H, \emptyset\}$. Using Bayes' rule, we derive the CRA's reputation after issuing an $H$-rating as:

$$
\mu_{t}^{H} \equiv \operatorname{prob}\left[\tau=e \mid r_{t}=H\right]=\frac{\mu_{t} \alpha}{\mu_{t} \alpha+\left(1-\mu_{t}\right)\left(\alpha+(1-\alpha) \tilde{p}_{t}\right)},
$$

where $\tilde{p}_{t}$ denotes the investors' beliefs about the CRA's rating strategy $p_{t}$. Note that issuing an $H$-rating lowers the CRA's reputation (i.e., $\mu_{t}^{H}<\mu_{t}$ ) if the opportunistic CRA issues such a rating for some type- $B$ firms (in addition to all type- $G$ firms). This loss of reputation reflects

\footnotetext{
${ }^{21}$ Recall that a firm that does not have a project in the first period still has a chance of investing in a type- $G$ project in the second period and, thus, has a positive value.
} 
the fact that, in equilibrium, an $H$-rating is more likely to be released by an opportunistic CRA than an ethical one, since an opportunistic CRA releases $H$-ratings also to bad firms with positive probability, whereas an ethical CRA never does.

After observing an $H$-rating (and updating the CRA's reputation), investors update the probability that the firm's investment project is of the good type as follows:

$$
\alpha_{t}^{H} \equiv \operatorname{prob}\left[\theta=G \mid r_{t}=H\right]=\mu_{t}^{H}+\left(1-\mu_{t}^{H}\right) \frac{\alpha}{\alpha+(1-\alpha) \tilde{p}_{t}} .
$$

Accordingly, the firm's (gross) market value is equal to the expected payoff from the investment project conditional on receiving an $H$-rating:

$$
V_{t}^{H}=\alpha_{t}^{H} q R
$$

which exceeds the amount $I$ invested in the project since $\alpha_{t}^{H} \geq \alpha$.

It is easy to verify that the CRA's reputation positively affects the value of a firm with a favorable credit rating.

Lemma 1. The value of an $H$-rated firm is an increasing function of the CRA's reputation, that is, $d V_{t}^{H} / d \mu_{t}^{H} \geq 0$.

In a rating system without unsolicited ratings, a lack of rating activity by the CRA (that is, the observation of an unrated firm, $r_{t}=\emptyset$ ) is also informative about the CRA's type and, hence, affects its reputation. ${ }^{22}$ This happens because the absence of a rating can mean either that a firm does not have access to an investment project and, hence, does not have any financing needs, or that the CRA offered to issue an $L$-rating and the firm declined the offer. From Bayes' rule, we have:

$$
\mu_{t}^{\emptyset} \equiv \operatorname{prob}\left[\tau=e \mid r_{t}=\emptyset\right]=\frac{\mu_{t}(1-\beta+(1-\alpha) \beta)}{\mu_{t}(1-\beta+(1-\alpha) \beta)+\left(1-\mu_{t}\right)\left(1-\beta+(1-\alpha) \beta\left(1-\tilde{p}_{t}\right)\right)} .
$$

\footnotetext{
${ }^{22}$ The absence of a rating, $r=\emptyset$, can be interpreted as a period of time in which the rating activity of the CRA is "lower than usual."
} 
The above equation shows that if the opportunistic CRA issues an $H$-rating for some type- $B$ firms (in addition to all type- $G$ firms), a lack of rating activity increases the CRA's reputation (i.e., $\mu_{t}^{\emptyset}>\mu_{t}$ ). This happens because a lack of rating activity signals to investors that the CRA refrained from issuing a potentially inflated rating, which is more likely to happen when the CRA is ethical.

Absence of rating activity also affects the value of unrated firms. From the investors' perspective, the value of an unrated firm is the weighted average of the value of a firm without an investment project (that never requested a rating) and the value of a firm with a project that was offered an $L$-rating by the CRA which was then declined by the firm. Our analysis below shows that the latter category only consists of type- $B$ firms which have zero value. In the first period, the value of an unrated firm is therefore equal to:

$$
V_{1}^{\emptyset}=\left(1-\beta_{1}^{\emptyset}\right) \bar{V}
$$

where:

$$
\beta_{t}^{\emptyset} \equiv \operatorname{prob}\left[\theta \neq N \mid r_{t}=\emptyset\right]=\mu_{t}^{\emptyset} \frac{(1-\alpha) \beta}{1-\beta+(1-\alpha) \beta}+\left(1-\mu_{t}^{\emptyset}\right) \frac{(1-\alpha) \beta\left(1-\tilde{p}_{t}\right)}{1-\beta+(1-\alpha) \beta\left(1-\tilde{p}_{t}\right)}
$$

That is, the probability $1-\beta_{1}^{\emptyset}$ represents the investors' updated belief that an unrated firm is of type $\theta=N$. The variable $\bar{V}$ denotes the value of a firm that does not have an investment project in the first period, which is given by:

$$
\bar{V}=\left(\alpha+(1-\alpha)\left(1-\mu_{1}^{\emptyset}\right) \tilde{p}_{2}\right) \beta\left(V_{2}^{H}-I-\phi_{2}\right)
$$

where $V_{2}^{H}-I-\phi_{2}$ represents the market value of an $H$-rated firm in the second period, net of the investment cost, $I$, and the fee paid to the CRA in the second period, $\phi_{2}$. The term $\left(\alpha+(1-\alpha)\left(1-\mu_{1}^{\emptyset}\right) \tilde{p}_{2}\right) \beta$ reflects the fact that a type- $G$ firm will receive an $H$-rating with probability one in the second period, whereas a type- $B$ firm will receive such a rating only 
with probability $p_{2}$ and only if the CRA turns out to be of the opportunistic type (which happens with probability $1-\mu_{1}^{\emptyset}$.

If an investment is made, which in equilibrium happens only if the firm obtains an $H$ rating, the project payoff is realized at the end of the period and becomes known to investors. After observing the outcome of the investment project, investors update once more the CRA's reputation. Since firms with good projects are successful with probability $q$, whereas firms with bad projects always fail, the CRA's updated reputation depends on whether the investment project succeeds $\left(\omega_{t}=S\right)$ or not $\left(\omega_{t}=F\right)$. Project success reveals the firm as being of type $G$ and the CRA's reputation becomes:

$$
\mu_{t}^{H, S} \equiv \operatorname{prob}\left[\tau=e \mid r_{t}=H, \omega_{t}=S\right]=\frac{\mu_{t} \alpha q}{\mu_{t} \alpha q+\left(1-\mu_{t}\right) \alpha q}=\mu_{t}
$$

The above equation shows that project success increases the CRA's reputation (i.e., $\mu_{t}^{H, S}>$ $\left.\mu_{t}^{H}\right)$, since opportunistic CRAs may issue $H$-ratings with positive probability to bad firms, which have a lower success probability. In addition, since in our simplified model only good projects succeed and (in equilibrium) all firms with good projects obtain an $H$-rating, the observation of a successful $H$-rated project restores the reputation of the CRA to its original level, that is, $\mu_{t}^{H, S}=\mu_{t}{ }^{23}$

If the project fails, the CRA's updated reputation is:

$$
\mu_{t}^{H, F} \equiv \operatorname{prob}\left[\tau=e \mid r_{t}=H, \omega_{t}=F\right]=\frac{\mu_{t} \alpha(1-q)}{\mu_{t} \alpha(1-q)+\left(1-\mu_{t}\right)\left(\alpha(1-q)+(1-\alpha) \tilde{p}_{t}\right)} .
$$

Project failure has an adverse effect on the CRA's reputation, since an ethical CRA never issues an $H$-rating for a firm with a bad project. This means that $H$-rated projects are more likely to fail when the rating is issued by the opportunistic CRA, which implies that

\footnotetext{
${ }^{23}$ Note that if type- $B$ projects also succeeded with positive probability, then the updated reputation $\mu_{t}^{H, S}$ would be strictly less than $\mu_{t}$, assuming that the opportunistic CRA engages in ratings inflation. This happens because, in this case, investors cannot distinguish ex post whether a successful project is of the good or bad type.
} 
$\mu_{t}^{H, F}<\mu_{t}^{H}$. Note that, when updating the CRA's reputation, investors take into account that the failure of an $H$-rated firm may be the result of "bad luck" (i.e., a good firm failing), rather than of "bad ratings" (i.e., inflated ratings for bad firms). This means that project failure, while negatively affecting the CRA's reputation, does not fully reveal the CRA's type to investors as long as the success probability of good firms, $q$, is strictly less than one.

We now turn to deriving the objective function of the opportunistic CRA. Proceeding backwards, in the second (and final) period, the CRA only cares about the profit that it generates from issuing a solicited rating in that period. Thus, the CRA's objective function is given by: ${ }^{24}$

$$
\pi_{2}\left(\mu_{2}\right)=\beta\left(\alpha+(1-\alpha) p_{2}\right) \phi_{2}
$$

Note that the period 2 profit depends on the CRA's reputation at the beginning of the period, $\mu_{2}$, through its effect on the fee $\phi_{2}$ that the CRA can charge firms for an $H$-rating.

In the first period, the opportunistic CRA chooses its rating policy to maximize the sum of the expected profit obtained in periods 1 and 2 :

$$
\begin{aligned}
\pi_{1}= & \alpha \beta\left(\phi_{1}+q \pi_{2}\left(\mu_{1}^{H, S}\right)+(1-q) \pi_{2}\left(\mu_{1}^{H, F}\right)\right) \\
& +(1-\alpha) \beta\left(p_{1}\left(\phi_{1}+\pi_{2}\left(\mu_{1}^{H, F}\right)\right)+\left(1-p_{1}\right) \pi_{2}\left(\mu_{1}^{\emptyset}\right)\right) \\
& +(1-\beta) \pi_{2}\left(\mu_{1}^{\emptyset}\right) .
\end{aligned}
$$

The three components of the opportunistic CRA's expected profit, $\pi_{1}$, represent the three cases in which the firm has a good project $(\theta=G)$, a bad project $(\theta=B)$, or no project $(\theta=N)$. If a type- $G$ firm requests a rating, which happens with probability $\alpha \beta$, the CRA always offers to issue an $H$-rating and thus earns a fee of $\phi_{1}$ in the first period. The expected second-period profit depends on whether the project succeeds $\left(\omega_{1}=S\right)$ or not $\left(\omega_{1}=F\right)$,

\footnotetext{
${ }^{24}$ For notational simplicity, this expression as well as the expression for the CRA's objective function in period $1, \pi_{1}$, reflect the conjecture that firms never acquire an $L$-rating at a positive fee (which will be confirmed to be correct in equilibrium).
} 
since the project outcome affects the CRA's reputation, $\mu_{1}^{H, \omega_{1}}, \omega_{1} \in\{S, F\}$. If the firm has a bad project, which happens with probability $(1-\alpha) \beta$, the CRA's expected profit depends on whether the CRA offers to issue an $H$-rating (with probability $p_{1}$ ) or an $L$-rating (with probability $\left.1-p_{1}\right)$. In the former case, the CRA earns a fee of $\phi_{1}$ in the first period and obtains an expected profit of $\pi_{2}\left(\mu_{1}^{H, F}\right)$ in the second period based on the updated reputation $\mu_{1}^{H, F}$, taking into account that bad projects always fail. In the latter case, the firm declines to acquire the offered $L$-rating and the CRA does not earn a rating fee in the first period. Its expected second-period profit is then a function of its updated reputation $\mu_{1}^{\emptyset}$. Finally, if the firm has no project, which happens with probability $1-\beta$, the firm remains unrated. In this case, the CRA's profit is given by the expected fee it earns in the second period, conditional on its reputation when no rating is issued in the first period.

We now turn to the firm's problem of whether to request a rating. A type- $G$ firm clearly prefers to do so: by requesting a rating, it reveals its type to the CRA and thus will be offered a favorable $H$-rating with probability one, which means that its net market value is equal to $V_{t}^{H}-I-\phi_{t}$. On the other hand, if it does not request a rating, the CRA will learn its type only with probability $\delta$ (in which case the CRA will again offer a favorable $H$-rating with probability one). Thus, there is a chance of $1-\delta$ that the firm will remain unrated, and that its net market value will only be $V_{t}^{\emptyset}<V_{t}^{H}-I-\phi_{t}$.

A type- $B$ firm faces a similar trade-off: since the firm can always refuse to acquire an $L$-rating if it is offered one, its payoff from requesting a rating can never be lower than that from not requesting one. This happens because if the firm requests a rating, it is offered an $H$-rating with probability $p_{t}$, leading to a market value of $V_{t}^{H}-I-\phi_{t}$. If the firm does not request a rating, it will be mistaken for a type- $N$ firm with probability $1-\delta$, reducing its market value to $V_{t}^{\emptyset}<V_{t}^{H}-I-\phi_{t}$, while with probability $\delta$ it is found to be of type $B$ and offered an $H$-rating by the CRA again with probability $p_{t}$, leading to a market value of $V_{t}^{H}-I-\phi_{t}$. Thus, both types of firms are strictly better off requesting a rating from the CRA. 
Having characterized the CRA's and the firm's problem, we are now in a position to solve for the equilibrium of our economy. The equilibrium concept we use is that of a Perfect Bayesian Equilibrium (PBE). Formally, a PBE of our economy consists of the firm's decision on whether to request a rating, the opportunistic CRA's rating policy, the firm's decision on whether to acquire the offered rating (and, hence, raise capital and invest in the project), and a system of beliefs formed by investors such that: (i) the choices made by the firm and the CRA maximize their respective utility, given the equilibrium choices of the other players and the set of equilibrium beliefs formed by investors in response to these choices; (ii) the beliefs of investors are rational given the equilibrium choices made by the CRA and the firm, and are formed using Bayes' rule; and (iii) any deviation from the equilibrium strategy by any party is met by beliefs of the other parties that yield a lower expected utility for the deviating party, compared to that obtained in equilibrium.

Proposition 1. In the solicited-only credit rating system, there exists a unique $p_{1} \in(0,1]$ such that the following strategies are an equilibrium:

(i) All firms with an investment project request a rating. Firms always acquire an $H$-rating if they are offered one; they never acquire an L-rating rating. Firms raise funds and invest in the project if and only if they obtain an $H$-rating.

(ii) In period 1, the opportunistic CRA offers an $H$-rating to type-G firms with probability one and to type- $B$ firms with probability $p_{1}>0$; it offers an L-rating to type- $B$ firms with probability $1-p_{1}$. The fee charged for a solicited $H$-rating is $\phi_{1}=\gamma\left(V_{1}^{H}-I-V_{1}^{\emptyset}\right)$. In period 2, the opportunistic CRA offers an H-rating to all firms that seek financing and charges a fee of $\phi_{2}=\gamma\left(V_{2}^{H}-I\right)$ for it.

These strategies are supported by the off-equilibrium beliefs that firms with an L-rating and firms seeking to raise funds without a rating are of type $B$ with probability one.

In a credit rating system with solicited ratings only, the credit rating policy of the oppor- 
tunistic CRA is determined as follows. First, the fee charged for an $H$-rating is a fraction $\gamma$ of the difference between the firm's market value associated with an $H$-rating, $V_{t}^{H}$, net of the investment cost, $I$, and its market value without such a rating, $V_{t}^{\emptyset}$. Thus, the equilibrium fee that the CRA charges firms for a solicited $H$-rating is equal to a fraction $\gamma$ of the "surplus value" created by the CRA, net of the "outside option" of the firm. In a credit rating system with solicited ratings only, the outside option of the firm is to remain unrated, generating a value to the firm of $V_{1}^{\emptyset}>0$ in the first period and of $V_{2}^{\emptyset}=0$ in the second period. The value of an unrated firm is positive in the first period because the market (correctly) believes that the firm may still obtain a project in the second period (which is the case for firms that do not have a project in the first period). The value of an unrated firm is zero in the second period because it is the last period of the game and the firm has no more chance of realizing a positive NPV project.

Given the equilibrium fee structure, the opportunistic CRA faces the following dynamic trade-off. On the one hand, it wants to maximize its current fees by offering an $H$-rating to all firms with financing needs. On the other hand, it wants to preserve, or rather improve, its reputation. Reputation is valuable to the CRA because a better reputation increases its credibility in the eyes of investors and, hence, the value of the securities that are marketed with an $H$-rating. In this way, a better reputation allows the CRA to charge firms a higher fee for an $H$-rating in the second period. The optimal rating policy balances these two effects.

The CRA's equilibrium behavior changes over time. In the second (and final) period, the opportunistic CRA has no reputational concerns anymore and thus finds it optimal to assign an $\mathrm{H}$-rating to all firms seeking financing. In the first period, the CRA always issues an $H$-rating for good firms. Note that while such a policy allows the CRA to pocket the fee $\phi_{1}$, it is potentially costly in terms of its reputation. Releasing an $H$-rating immediately reduces the CRA's reputation from $\mu_{1}$ to $\mu_{1}^{H}$. This loss of reputation is mitigated by the fact that projects of good firms succeed with positive probability and the CRA's reputation recovers if the project is revealed as successful $\left(\omega_{1}=S\right)$. However, it never reaches the level that 
the CRA could have achieved by refusing to release an $H$-rating, that is, $\mu_{1}^{H, S}<\mu_{1}^{\emptyset}$. If the project fails $\left(\omega_{1}=F\right)$, the CRA is exposed to a further loss of reputation, since $\mu_{1}^{H, F}<\mu_{1}^{H, S}$. Thus, by issuing an $H$-rating for a good firm the CRA puts its reputation at risk. The fee $\phi_{1}$ charged for a solicited $H$-rating compensates the CRA for this risk.

The opportunistic CRA also issues $H$-ratings for some bad firms. The equilibrium value of $p_{1}$ trades off the benefits and costs from releasing an $H$-rating rather than an $L$-rating. The benefit of this strategy is again that the CRA can pocket the fee $\phi_{1}$. The cost of this strategy is the loss of future profits due to a lower reputation (described above), which is now aggravated by the fact that the project of a bad firm fails with probability one. In contrast, if the CRA decides to offer the firm an $L$-rating, the firm will decline the offer and remain unrated, with the effect of increasing the CRA's reputation, since $\mu_{1}^{\emptyset}>\mu_{1}^{H, F}$. This increase in reputation follows directly from the fact that a lack of rating activity is more likely to be observed for an ethical CRA than an opportunistic one.

The opportunistic CRA's incentive to engage in ratings inflation (by issuing $H$-ratings for bad firms) ultimately depends on the effectiveness of reputation as a disciplining device, which in turn depends on the loss of reputation caused by the failure of highly rated firms. Since good firms fail with positive probability, this loss of reputation is dampened by the investors' inability to unambiguously attribute a failure to "bad ratings" (i.e., to ratings inflation) rather than to "bad luck."

Proposition 1 shows that the opportunistic CRA offers an $H$-rating to bad firms with strictly positive probability. The reason is that if it were to mimic the rating strategy of the ethical CRA (and never to issue an $H$-rating for bad firms), reputation would play no role, since both types of CRA would adhere to the same rating policy. Thus, the failure of highly rated firms would always be ascribed to "bad luck" rather than to "bad ratings" (which would not occur in equilibrium), with no effect on the CRA's reputation. Absent the disciplining effect of reputation, the opportunistic CRA would therefore always have an incentive to engage in ratings inflation. This argument shows that the imperfect (ex post) 
observability of a firm's project quality by investors - the project outcome does not fully reveal the firm's type - essentially limits the effectiveness of reputation as a disciplining device and that ratings inflation is therefore an endemic phenomenon of the credit rating process.

In our model, the equilibrium quality of credit ratings (i.e., the "credit rating standard") can be characterized by $1-p_{1}$, the probability that the opportunistic CRA refuses to issue an $H$-rating for a bad firm. The following proposition presents comparative statics results for the CRA's credit rating standard with respect to changes in the model primitives $R, q$, $\gamma$, and $\mu_{1}$.

Proposition 2. In the solicited-only credit rating system, the credit rating standard 1 $p_{1}$ is decreasing in the payoff $R$ of successful investment projects, decreasing in the success probability $q$ of type- $G$ firms for low values of $q$, decreasing in the fraction $\gamma$ of the surplus value captured by the CRA, increasing in the CRA's reputation $\mu_{1}$ for low values of $\mu_{1}$, and decreasing in $\mu_{1}$ for high values of $\mu_{1}$.

The rating strategy $p_{1}$ is determined by the first order condition of the maximization of the CRA's expected profit in equation (11), which (in equilibrium) is given by:

$$
V_{1}^{H}-I-V_{1}^{\emptyset}-\beta\left(V_{2}^{H}\left(\mu_{1}^{\emptyset}\right)-V_{2}^{H}\left(\mu_{1}^{H, F}\right)\right)=0
$$

where $V_{2}^{H}\left(\mu_{2}\right)$ denotes the value of an $H$-rated firm in period 2 given that the CRA's reputation equals $\mu_{2}$. Inspection of equation (12) allows us to identify the factors that affect the equilibrium credit rating standard, $1-p_{1}$. An increase in the project payoff $R$ increases the market value of $H$-rated firms, $V_{1}^{H}$ and $V_{2}^{H}$. However, it also increases the value of a firm's outside option in period 1 of remaining unrated, $V_{1}^{\emptyset}$. The former effect increases the firm's net surplus, while the latter effect decreases it. The net effect, however, is positive, which means that an increase in $R$ increases the maximum fee that firms are willing to pay for an $H$-rating and, thus, the surplus value that the CRA can extract. This increase in the first-period fee has to be contrasted with the increase in the second-period fee that the CRA 
foregoes by issuing an inflated rating. Releasing an $H$-rating for a type- $B$ firm lowers the CRA's reputation in period 2 from $\mu_{1}^{\emptyset}$ to $\mu_{1}^{H, F}$, thereby reducing its expected income from second-period rating fees by $\beta\left(V_{2}^{H}\left(\mu_{1}^{\emptyset}\right)-V_{2}^{H}\left(\mu_{1}^{H, F}\right)\right)$. While this reduction in expected second-period fees also increases in the project payoff $R$, in equilibrium it is dominated by the increase in first-period fees. This makes it more profitable for the opportunistic CRA to issue inflated ratings for bad firms and, hence, leads to a lower credit rating standard (i.e., a greater $p_{1}$ ). This property has the interesting implication that, if the project payoff is positively related to the business cycle, credit rating standards are countercyclical. This means that rating agencies are more likely to issue inflated ratings during periods of economic expansion, which may lead to lending booms that are associated with lower-quality investments and greater subsequent failures of highly rated securities. ${ }^{25}$

An increase in the success probability $q$ of type- $G$ firms has an ambiguous effect on the credit rating standard. On the one hand, similar to an increase in $R$, it increases the expected project payoff and, thus, the maximum fee that firms are willing to pay for an $H$-rating. All else equal, this again makes it more profitable for the CRA to issue inflated ratings. On the other hand, a higher success probability $q$ means that good projects fail less often, making it easier for investors to detect ratings inflation after a project fails: it is straightforward to show that the posterior probability $\mu_{1}^{H, F}$ is a decreasing function of $q$. This second effect makes it more costly for the CRA to issue an $H$-rating for a type- $B$ firm. When the success probability $q$ is sufficiently small, the first effect always dominates the second one, causing the credit rating standard to be a decreasing function of $q$. For larger values of $q$, the CRA has to balance the benefits of higher current fees against a more severe reputation loss after a failed project. When the latter exceeds the former, the credit rating standard increases in the success probability $q$.

An increase in the CRA's bargaining power $\gamma$ always promotes ratings inflation and, thus, reduces the rating standard. This happens because a higher value of $\gamma$ allows the CRA

\footnotetext{
${ }^{25}$ For a similar result, see Mathis, McAndrews, and Rochet (2009) and Opp, Opp, and Harris (2012).
} 
to extract a larger fraction of the surplus value from an $H$-rated firm in period 2 , thereby reducing the value of an unrated firm in period $1, V_{1}^{\emptyset}$.

Finally, when the CRA's reputation is sufficiently small (i.e., when $\mu_{1}$ is close to zero) or when it is sufficiently large (i.e., when $\mu_{1}$ is close to one), the informativeness of the CRA's rating record about its type is low. This implies that the CRA's rating strategy has (almost) no effect on its reputation, which weakens the disciplinary role of reputation and leads to a less stringent rating standard. ${ }^{26}$

\section{The Credit Rating System with Unsolicited Ratings}

In a credit rating system that incorporates unsolicited ratings, rating agencies have the ability to issue ratings even if not sponsored by firms. To allow for this possibility, we modify our basic model as follows. If a firm declines the CRA's offer to purchase a rating $r \in\{H, L\}$, the CRA can then decide to publish an unsolicited rating $r \in\{h, \ell\}$ at no cost to the firm. ${ }^{27}$ Since, as we will show below, no unsolicited $h$-ratings (and, again, no solicited $L$-ratings) are issued in equilibrium, the opportunistic CRA's rating policy in period $t$ can be characterized by the vector $\left\{\hat{p}_{t}^{\theta}, \hat{u}_{t}^{\theta}\right\}$, where $\hat{p}_{t}^{\theta}$ denotes the probability that the CRA offers an $H$-rating to a firm of type $\theta \in\{G, B\}$, and $\hat{u}_{t}^{\theta}$ the probability that it issues an unsolicited $\ell$-rating if the firm refuses to acquire a solicited rating. ${ }^{28}$ Thus, for ease of exposition, we again focus our discussion on the case where no firm acquires an $L$-rating, and type- $G$ firms request a rating and are offered an $H$-rating with probability one (i.e., $\hat{p}_{t}^{G}=1$ ). As in the previous section, we let $\hat{\phi}_{t}$ denote the fee that the CRA charges for an $H$-rating and $\hat{p}_{t}$ the probability that the opportunistic CRA offers such a rating to a type- $B$ firm.

\footnotetext{
${ }^{26}$ Since $p_{1}$ converges to 1 as $\mu_{1}$ goes to 0 or 1 , the credit rating standard $1-p_{1}$ increases in $\mu_{1}$ for low values of $\mu_{1}$ and decreases in $\mu_{1}$ for high values of $\mu_{1}$.

${ }^{27}$ Recall that a credit rating can be offered to the firm either if the firm has requested it (in which case the CRA learns the firm's type) or if the firm has not requested it and the CRA has observed an informative signal about the firm's type (which happens with probability $\delta$ ).

${ }^{28}$ We use the "hat" symbol to differentiate the CRA's strategy in the rating system with unsolicited ratings from its strategy in the solicited-only system.
} 
The possibility of releasing unsolicited credit ratings changes the CRA's strategy space, affecting the investors' updating process about the CRA's reputation and, hence, firm valuations and firm behavior. The key difference with the solicited-only rating system is that firms that are offered an $L$-rating may no longer be able, by rejecting the offer, to pool with type- $N$ firms that do not have investment projects if the CRA decides to issue an unsolicited

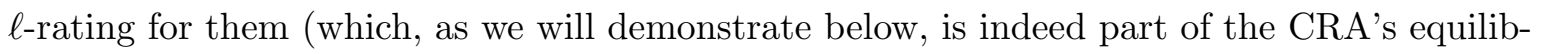
rium strategy). Thus, the ability of the CRA to issue an unsolicited $\ell$-rating changes a firm's "outside option."

In a credit rating system with unsolicited ratings, it may therefore no longer be optimal for a type- $B$ firm to always request a credit rating. This is because by requesting a rating the firm reveals its type to the CRA, which means that (in equilibrium) it will receive an unsolicited $\ell$-rating if it is not offered a solicited $H$-rating. In contrast, by not requesting a rating, the firm still has the chance to remain pooled with type- $N$ firms if the CRA does not observe its type, thereby avoiding an $\ell$-rating. Thus, if the probability $\delta$ that the CRA observes a signal revealing the firm's type is sufficiently low, it may be optimal for a type- $B$ firm not to request a rating. We let $\hat{\lambda}_{t}$ denote the probability that a type- $B$ firm requests a rating in period $t$ (which will be determined in equilibrium below).

Issuing an unsolicited rating affects the value of the firm and, at the same time, reveals information about the CRA's type. After observing an unsolicited $\ell$-rating, investors update the CRA's reputation as follows:

$$
\hat{\mu}_{t}^{\ell} \equiv \operatorname{prob}\left[\tau=e \mid r_{t}=\ell\right]=\frac{\mu_{t} \Lambda_{t}^{B}}{\mu_{t} \Lambda_{t}^{B}+\left(1-\mu_{t}\right) \Lambda_{t}^{B}\left(1-\tilde{p}_{t}\right) \tilde{u}_{t}^{B}}
$$

where $\Lambda_{t}^{B}=(1-\alpha) \beta\left(\tilde{\lambda}_{t}+\left(1-\tilde{\lambda}_{t}\right) \delta\right)$ denotes the fraction of firms known to be of type $B$ by the CRA - either because they requested a rating (with probability $\tilde{\lambda}_{t}$ ) or, if not, because the CRA observed an informative signal about their type (with probability $\left(1-\tilde{\lambda}_{t}\right) \delta$ ). As before, $\tilde{p}_{t}$ denotes the investors' beliefs about the opportunistic CRA's equilibrium choice of 
$\hat{p}_{t} ; \tilde{u}_{t}^{B}$ and $\tilde{\lambda}_{t}$ now denote their beliefs about $\hat{u}_{t}^{B}$ and $\hat{\lambda}_{t}$, respectively.

Interestingly, the possibility of releasing unsolicited ratings affects the CRA's reputation also when no rating is released (i.e., when $r_{t}=\emptyset$ ):

$$
\hat{\mu}_{t}^{\emptyset} \equiv \operatorname{prob}\left[\tau=e \mid r_{t}=\emptyset\right]=\frac{\mu_{t} \Lambda_{t}^{N}}{\mu_{t} \Lambda_{t}^{N}+\left(1-\mu_{t}\right)\left(\Lambda_{t}^{N}+\Lambda_{t}^{B}\left(1-\tilde{p}_{t}\right)\left(1-\tilde{u}_{t}^{B}\right)\right)}
$$

where $\Lambda_{t}^{N}=1-\beta+(1-\alpha) \beta\left(1-\tilde{\lambda}_{t}\right)(1-\delta)$ denotes the fraction of firms believed not to have an investment project by the CRA. It reflects the fact that while an ethical CRA issues a rating for all firms known to have access to an investment project, an opportunistic CRA may choose not to do so.

It is easy to verify that the possibility of releasing unsolicited ratings impacts the CRA's reputation after issuing an $H$-rating only through its effect on (the investors' beliefs about) the probability that a type- $B$ firm is offered an $H$-rating, which depends on the firm's decision to request a rating. If a bad firm requests a rating, the probability that it is offered an $H$ rating is $\hat{p}_{t}$; if it does not request a rating, the probability is only $\delta \hat{p}_{t}$. Thus, the expressions for $\hat{\mu}_{t}^{H}, \hat{\mu}_{t}^{H, S}$, and $\hat{\mu}_{t}^{H, F}$ are identical to those in equations (1), (8), and (9) when $\tilde{p}_{t}$ is replaced by $\left(\tilde{\lambda}_{t}+\left(1-\tilde{\lambda}_{t}\right) \delta\right) \tilde{p}_{t}$. The same is true for the updated probability $\hat{\alpha}_{t}^{H}$ that a firm with an $H$-rating is of type $G$ in equation (2).

The objective function of the opportunistic CRA in a credit rating system with unsolicited ratings is similar to the one derived for the solicited-only rating system. In the second period, the CRA's profit again equals the fee that it earns by selling an $H$-rating to a firm. ${ }^{29}$ In the first period, the objective function now takes into account the possibility that the CRA issues an unsolicited $\ell$-rating and that (type- $B$ ) firms may therefore prefer not to request a

\footnotetext{
${ }^{29}$ In the second period, all firms with an investment project request a rating (i.e., $\hat{\lambda}_{2}=1$ ), since the value of their outside option, $\hat{V}_{2}^{\emptyset}$, is zero. This means that the CRA's profit $\hat{\pi}_{2}$ is again given by equation (10).
} 
rating. Thus, the CRA's expected profit in equation (11) has to be modified as follows:

$$
\begin{aligned}
\hat{\pi}_{1}= & \alpha \beta\left(\hat{\phi}_{1}+q \hat{\pi}_{2}\left(\hat{\mu}_{1}^{H, S}\right)+(1-q) \hat{\pi}_{2}\left(\hat{\mu}_{1}^{H, F}\right)\right) \\
& +\Lambda_{1}^{B}\left(\hat{p}_{1}\left(\hat{\phi}_{1}+\hat{\pi}_{2}\left(\hat{\mu}_{1}^{H, F}\right)\right)+\left(1-\hat{p}_{1}\right)\left(\hat{u}_{1}^{B} \hat{\pi}_{2}\left(\hat{\mu}_{1}^{\ell}\right)+\left(1-\hat{u}_{1}^{B}\right) \hat{\pi}_{2}\left(\hat{\mu}_{1}^{\emptyset}\right)\right)\right) \\
& +\Lambda_{1}^{N} \hat{\pi}_{2}\left(\hat{\mu}_{1}^{\emptyset}\right) .
\end{aligned}
$$

The possibility of receiving an unsolicited $\ell$-rating also affects the firm's decision of whether to request a rating when its project is of type $B$. By not requesting a rating, a bad firm may be able to conceal its type from the CRA. In particular, it will be mistaken for a type- $N$ firm with probability $1-\delta$, which means that it will not receive a credit rating in this case. If this happens, its (gross) market value in the first period is equal to:

$$
\hat{V}_{1}^{\emptyset}=\left(1-\hat{\beta}_{1}^{\emptyset}\right) \hat{\bar{V}}=\left(1-\hat{\beta}_{1}^{\emptyset}\right)\left(\alpha+(1-\alpha)\left(1-\hat{\mu}_{1}^{\emptyset}\right) \tilde{p}_{2}\right) \beta\left(\hat{V}_{2}^{H}\left(\hat{\mu}_{1}^{\emptyset}\right)-I-\hat{\phi}_{2}\right),
$$

where $\hat{V}_{2}^{H}\left(\hat{\mu}_{1}^{\emptyset}\right)=\hat{\alpha}_{2}^{H}\left(\hat{\mu}_{1}^{\emptyset}\right) q R$ and $\hat{\beta}_{1}^{\emptyset}$ denotes the probability that an unrated firm has an investment project, which is given by:

$$
\hat{\beta}_{1}^{\emptyset}=\hat{\mu}_{1}^{\emptyset} \frac{(1-\alpha) \beta\left(1-\tilde{\lambda}_{1}\right)(1-\delta)}{\Lambda_{1}^{N}}+\left(1-\mu_{1}^{\emptyset}\right) \frac{(1-\alpha) \beta\left(1-\tilde{\lambda}_{1}\right)(1-\delta)+\Lambda_{1}^{B}\left(1-\tilde{p}_{1}\right)\left(1-\tilde{u}_{1}^{B}\right)}{\Lambda_{1}^{N}+\Lambda_{1}^{B}\left(1-\tilde{p}_{1}\right)\left(1-\tilde{u}_{1}^{B}\right)} .
$$

Thus, in the first period, the value of an unrated firm exceeds that of an $\ell$-rated firm, which is zero since the firm is known to be bad. On the other hand, if a type- $B$ firm requests a rating, it has a chance of receiving an $H$-rating from an opportunistic CRA (with probability $\left.\left(1-\mu_{1}\right) \hat{p}_{1}\right)$, but it may also receive an $\ell$-rating (with probability $\left.1-\left(1-\mu_{1}\right) \hat{p}_{1}\right)$. Since $\hat{V}_{1}^{H}>\hat{V}_{1}^{\emptyset}>\hat{V}_{1}^{\ell}=0$, the trade-off that a type- $B$ firm faces in period 1 is non-trivial. Its optimal decision of whether to request a rating has to be jointly determined with the CRA's equilibrium rating policy. Type- $G$ firms, on the other hand, face the same problem as in the solicited-only rating system: since they receive an $H$-rating with probability one when 
their type is known to the CRA, they can only be worse off by not requesting a rating. In the second period, the value of an unrated firm is zero, since the firm has no more chance of realizing a positive NPV project. Thus, all firms with investment projects are better off requesting a rating in the final period.

The following proposition characterizes the equilibrium in a credit rating system that allows rating agencies to issue unsolicited ratings.

Proposition 3. In the credit rating system with unsolicited ratings, if $\beta>\alpha /(1-\alpha)$ there exists a pair $\left(\hat{p}_{1}, \hat{\lambda}_{1}\right) \in[0,1]^{2}$ and a threshold $\bar{\mu}>0$ such that, for any $\mu_{1}<\bar{\mu}$, the following strategies are an equilibrium:

(i) Type-G firms always request a rating; type- $B$ firms request a rating with probability $\hat{\lambda}_{1}$ in period 1, and with probability one in period 2. Firms always acquire an $H$-rating if they are offered one; they never acquire an L-rating rating. Firms raise funds and invest in the project if and only if they obtain an $H$-rating.

(ii) In period 1, the opportunistic CRA offers an $H$-rating to firms known to be of type $G$ with probability one and to firms known to be of type $B$ with probability $\hat{p}_{1} \in(0,1)$; it offers an L-rating to firms known to be of type $B$ with probability $1-\hat{p}_{1}$. The fee charged for a solicited $H$-rating is $\hat{\phi}_{1}=\gamma\left(\hat{V}_{1}^{H}-I\right)$. If a firm rejects the offer to acquire a solicited rating, the CRA issues an unsolicited $\ell$-rating for the firm with probability one (i.e., $\hat{u}_{1}^{G}=\hat{u}_{1}^{B}=1$ ). In period 2, the opportunistic CRA offers an H-rating to all firms that seek financing and charges a fee of $\hat{\phi}_{2}=\gamma\left(\hat{V}_{2}^{H}-I\right)$ for it.

These strategies are supported by the off-equilibrium beliefs that firms with an L-rating and firms seeking to raise funds without a rating are of type $B$ with probability one, and that a CRA issuing an unsolicited h-rating is of the ethical type with probability $\mu_{1}$ (i.e., by the passive conjecture). Further, if $I<\alpha^{2} q R$, the pair $\left(\hat{p}_{1}, \hat{\lambda}_{1}\right)$ is unique.

The ability to issue unsolicited credit ratings affects the firms' and the opportunistic 
CRA's equilibrium strategies as follows. Firms of type $G$ again prefer to request a rating, knowing that they will be offered an $H$-rating for sure in this case, rather than not to request a rating and risk being mistaken for a type- $N$ firm (which happens with probability $1-\delta$ ). In addition, if the CRA is likely to be of the opportunistic type, a type- $G$ firm is better off acquiring a solicited $H$-rating for a fee of $\hat{\phi}_{t}$, rather than refusing the CRA's offer, hoping to receive an unsolicited $h$-rating from an ethical CRA for free. For low values of $\mu_{t}$, the firm's payoff in the former case, which equals $(1-\gamma)\left(\hat{V}_{t}^{H}-I\right)$, exceeds its expected payoff in the latter case given by $\mu_{t}\left(\hat{V}_{t}^{h}-I\right)$, where $\hat{V}_{t}^{h}$ is the off-equilibrium market value of a firm with an unsolicited $h$-rating. In contrast, type- $B$ firms play a mixed strategy in period 1 and request a rating with probability $\hat{\lambda}_{1}$. In an interior equilibrium (with $0<\hat{\lambda}_{1}<1$ ), a type- $B$ firm is indifferent between requesting a rating and revealing its type to the CRA, and not requesting a rating and being mistaken for an unrated type- $N$ firm with probability $1-\delta$.

Similar to the case with solicited ratings only, the CRA offers to issue a solicited $H$-rating for good firms (for a fee of $\hat{\phi}_{1}$ ) with probability one and for bad firms with strictly positive probability $\hat{p}_{1}$. Firms that decline the offer always receive an unsolicited $\ell$-rating (at no cost). Releasing an $H$-rating again lowers the CRA's reputation, where the loss of reputation is aggravated if the project is a failure, and is mitigated if the project turns out to be a success. In contrast, an unsolicited $\ell$-rating has a positive effect on the CRA's reputation, even more so than not issuing a rating (or issuing an unsolicited $h$-rating). This can be seen from equations (1), (13), and (14), which show that in equilibrium $\hat{\mu}_{1}^{H}<\hat{\mu}_{1}^{\emptyset}=\mu_{1}<\hat{\mu}_{1}^{\ell}$. This result reflects the fact that, in equilibrium, unsolicited $\ell$-ratings are more likely to be released by an ethical CRA than by an opportunistic CRA: the former issues unsolicited $\ell$-ratings for all firms known to be of type $B$, whereas the latter does so only for a fraction $1-\hat{p}_{1}$ of them. Thus, the issuance of an unsolicited $\ell$-rating proves to be a more effective way for the CRA to improve its reputation in the eyes of investors than the absence of a solicited $H$-rating: it sends a strong "signal" to investors that the CRA resisted the temptation to issue a (possibly) inflated $H$-rating. 
It is interesting to note that the beneficial effect of unsolicited $\ell$-ratings on the CRA's reputation makes $\ell$-ratings a credible threat to firms that refuse to acquire a solicited rating. The threat is credible precisely because these ratings improve the CRA's reputation. This is true for type- $B$ firms as well as for type- $G$ firms, since neither type of firm can raise the necessary funds to finance its project after receiving an $\ell$-rating, which makes any further updating of the CRA's reputation by investors impossible. ${ }^{30}$ This threat, however, remains "latent" and is not carried out in equilibrium, since all firms are willing to acquire a solicited $H$-rating (for a fee of $\hat{\phi}_{1}$ ) if they are offered one. This means that unsolicited ratings are not directly punitive in the sense that they are not downward biased relative to the firm's true quality, as the following corollary shows.

Corollary 1. In equilibrium, unsolicited ratings are only issued for type-B firms. Thus, unsolicited ratings are associated with lower firm valuations, compared to solicited ratings. They are, however, not downward biased relative to the firms' true quality.

Several empirical papers have shown that unsolicited ratings are significantly lower than solicited ratings (e.g., Poon, 2003; Gan, 2004; Poon and Firth, 2005; Van Roy, 2006; Bannier, Behr, and Güttler, 2010). ${ }^{31}$ However, the reason for this difference is not well understood. Using S\&P's bond ratings on the international market, Poon (2003) reports that issuers who chose not to obtain rating services from $\mathrm{S} \& \mathrm{P}$ have weaker financial profiles. Her analysis indicates, however, that the difference in ratings cannot be explained by this self-selection bias and she concludes that unsolicited ratings are downward biased. Gan (2004) uses an ex post regression approach and finds no significant difference between the performance of

\footnotetext{
${ }^{30}$ It is straightforward to show that this argument remains valid in the more general setting in which $\ell$-rated firms are still able to obtain financing (and succeed with a (small) positive probability). The reason is that, in equilibrium, investors attribute the success of an $\ell$-rated firm to "good luck" rather than to an incorrect rating. This means that the CRA's reputation following the issuance of an $\ell$-rating is unaffected by the subsequent observation of a successful project outcome (i.e., $\hat{\mu}_{t}^{\ell}=\hat{\mu}_{t}^{\ell, S}$ ), making the CRA's threat credible even when firms are still able to invest after obtaining an unfavorable unsolicited rating.

${ }^{31}$ For example, using international data from 1998 to 2000, Poon (2003) shows that while solicited ratings are more common for investment-grade issues ( $55 \%$ of ratings in this category are solicited), unsolicited ratings are the dominant rating type for speculative-grade issues (68\% of ratings in this category are unsolicited).
} 
issuers with solicited and unsolicited ratings. This result leads her to reject the "punishment hypothesis" - that is, the hypothesis that rating agencies use unfavorable unsolicited ratings to punish firms that refuse to solicit a rating - in favor of the self-selection hypothesis. Bannier, Behr, and Güttler (2010), however, cannot reject the punishment hypothesis for their sample.

Our paper suggests an alternative explanation for these findings. While unsolicited ratings are lower in our model, they are not downward biased. Rather, they reflect the lower quality of issuers. As a result, while issuers with unsolicited ratings should have weaker financial profiles, we should not observe any significant differences between their ex post performance and that of issuers with solicited ratings, once we control for their rating level. In other words, there is no systematic bias. This argument, however, does not imply that rating agencies do not use unsolicited ratings to threaten issuers to pay higher fees for more favorable ratings. In fact, our analysis shows that, although "punishment" is a latent threat (i.e., it is an out-ofequilibrium outcome) and thus not directly observed by investors, it still plays an important role in the credit rating process as a credible threat. As we will show in Section 5, the presence of such a credible threat allows CRAs to charge higher fees for solicited ratings and, thus, to extract more surplus from firms.

We conclude this section by deriving comparative statics results for the credit rating standard in the system that incorporates unsolicited ratings. The credit rating standard is again characterized by the probability that the opportunistic CRA does not offer a favorable $H$-rating to a firm known to be of type $B$, that is, by $1-\hat{p}_{1}$.

Proposition 4. In the credit rating system with unsolicited ratings, the credit rating standard $1-\hat{p}_{1}$ is decreasing in the payoff $R$ of successful investment projects, decreasing in the success probability $q$ of type-G firms for low values of $q$, increasing in the CRA's reputation $\mu_{1}$ for low values of $\mu_{1}$, and decreasing in $\mu_{1}$ for high values of $\mu_{1}$. It is independent of the fraction $\gamma$ of the surplus value captured by the CRA. 
As in the solicited-only rating system, the credit rating standard is decreasing in the project payoff $R$ and the success probability $q$ (for low values of $q$ ). This means that credit ratings are again more likely to be inflated during periods of economic expansion (i.e., when $R$ is high), which are then followed by an increase in default rates of highly rated securities. However, in contrast to the earlier case, the credit rating standard is independent of $\gamma$, the fraction of the surplus value captured by the CRA. The reason is that, in a rating system with unsolicited ratings, firms that refuse to acquire a solicited $H$-rating receive an unsolicited $\ell$-rating. Since in equilibrium $\ell$-ratings are only issued for type- $B$ firms, this means that the value of a firm's outside option is zero, the value of a type- $B$ firm. Thus, the CRA's rating fees in both periods, which are given by $\hat{\phi}_{t}=\gamma\left(\hat{V}_{t}^{H}-I\right)$, are directly proportional to $\gamma$. This implies that $\gamma$ has no effect on the CRA's optimal choice of rating strategy $\hat{p}_{1} \cdot{ }^{32}$ Finally, the credit rating standard is again increasing in the CRA's reputation $\mu_{1}$ for low values of $\mu_{1}$, and decreasing in $\mu_{1}$ for high values of $\mu_{1}$, for the same reasons as in the solicited-only rating system.

\section{$5 \quad$ Fees, Rating Standards, and Social Welfare}

In this section, we compare the fee structure and the rating standard of the credit rating system with unsolicited ratings to those of the solicited-only rating system and derive implications for social welfare.

We begin with the rating fees that the CRA can charge under these two systems. The following proposition shows that the ability to release unsolicited $\ell$-ratings allows the opportunistic CRA to charge higher fees for solicited $H$-ratings.

Proposition 5. For a given reputation $\mu_{1}$ of the CRA, the fee charged for solicited $H$-ratings is higher in a rating system that allows for unsolicited ratings than in a solicited-only credit

\footnotetext{
${ }^{32}$ In contrast, in the solicited-only rating system, the first-period fee $\phi_{1}$ is a decreasing function of the value of an unrated firm, $V_{1}^{\emptyset}$, which is itself a decreasing function of $\gamma$.
} 
rating system, that is, $\hat{\phi}_{1}>\phi_{1}$.

Proposition 5 provides one of the key insights of this paper. The ability to issue unsolicited ratings is valuable to the CRA because it enables the CRA to charge higher fees and, hence, to extract more surplus from rated firms. This happens because in a solicited-only credit rating system firms have the option to avoid a low rating by refusing to be rated by the CRA. In this case, the value of the outside option for a firm is the value of an unrated firm, given by equation (5). The CRA's opportunity to issue unsolicited $\ell$-ratings eliminates this option and lowers the value of a firm's outside option to the value of a bad firm, which is zero. This increases the value of a favorable $H$-rating and, hence, the fee that the firm is willing to pay for it. ${ }^{33}$

We now turn to a comparison of the extent of ratings inflation under the two different rating systems and discuss their implications for social welfare. In our model, the extent of ratings inflation can be measured by the probability that a type- $B$ firm obtains an $H$-rating, which is equal to $p_{1}$ in the solicited-only rating system and to $\left(\hat{\lambda}_{1}+\left(1-\hat{\lambda}_{1}\right) \delta\right) \hat{p}_{1}$ in the rating system with unsolicited ratings.

Proposition 6. If the fraction of the surplus value captured by the $C R A, \gamma$, is sufficiently large, the extent of ratings inflation is greater in the solicited-only rating system. For low values of $\gamma$, it can be greater in the rating system that incorporates unsolicited ratings.

The opportunistic CRA's incentive to inflate its ratings are determined by the tradeoff between rating fees and the benefits of reputation building. We know from Proposition 5 that the ability to issue unsolicited ratings enables the CRA to charge higher fees for solicited $H$-ratings. Thus, compared to the solicited-only rating system, the opportunistic CRA's marginal benefit from issuing an inflated $H$-rating for a type- $B$ firm is greater in the case when unsolicited ratings are permitted.

\footnotetext{
${ }^{33}$ Note that this result critically depends on the fact that the issuance of an unsolicited $\ell$-rating is a credible threat to firms. As discussed in the previous section, releasing an $\ell$-rating is an optimal response for the CRA to a firm's decision not to obtain a solicited rating, independent of the quality of the firm's investment project.
} 
The effect of the CRA's rating policy on its reputation is more subtle. In the solicited-only rating system, the alternative to issuing an $H$-rating is to leave the firm unrated (by offering an $L$-rating to the firm), which we know to have a beneficial effect on the CRA's reputation. In contrast, in the system with unsolicited ratings, the possibility of releasing an unsolicited $\ell$-rating allows the CRA to boost its reputation to a greater extent than it otherwise could in the absence of such ratings. Intuitively, this happens because in the solicited-only regime, the set of unrated firms contains both firms with bad projects that refuse to acquire an $L$-rating and firms that do not have a project, making the investors' inference process noisier.

In equilibrium, the CRA's choice of $\hat{p}_{1}$ balances these two effects and trades off the benefit of a higher rating fee against the negative effects on its reputation. When the fraction of the surplus value captured by the CRA, $\gamma$, is large, the difference between the fees that the CRA charges for an $H$-rating in the two rating systems is small (see Propositions 1 and 3), reducing the difference in the benefits of ratings inflation in the two regimes. ${ }^{34}$ On the other hand, the ability to release unsolicited $\ell$-ratings provides a greater reputation benefit to the CRA with respect to leaving the firm unrated (as discussed above). When this reputation effect dominates the difference in fees, the CRA optimally chooses to issue less inflated ratings in the rating system with unsolicited ratings.

Proposition 6 challenges the argument that the higher fees associated with a rating system that allows for unsolicited ratings compromises the agencies' rating standards and leads to more ratings inflation. Our analysis suggests that this is not necessarily the case. In particular, we show that the extent of ratings inflation can be less in a system with unsolicited ratings than in a solicited-only system, even though rating fees in the former system exceed those in the latter. The reason is that, in a system with unsolicited ratings, CRAs benefit more from the increased reputation associated with releasing unsolicited $\ell$-ratings. Thus, under certain conditions, this disciplinary role of reputation leads to less ratings inflation.

\footnotetext{
${ }^{34}$ This happens because a large $\gamma$ means that the value of an unrated firm in the solicited-only system is close to zero, that is, close to the value of a firm with an unsolicited $\ell$-rating.
} 
Assuming that social welfare is utilitarian (i.e., the social welfare function is equally weighted), social welfare in our model equals the expected NPV of all investment projects undertaken by firms. The following result therefore follows immediately from Proposition 6 .

Proposition 7. If the fraction of the surplus value captured by the CRA, $\gamma$, is sufficiently large, the adoption of unsolicited credit ratings leads to an improvement in social welfare. For low values of $\gamma$, it can lead to a reduction in social welfare.

Proposition 7 sheds some light on the recent debate on whether the adoption of unsolicited ratings should be encouraged or not, and on how such a change would affect social welfare. Our analysis shows that the answer to these questions depends on the fraction of the firms' surplus extracted by the CRA and, hence, the CRA's bargaining power. When the CRA captures a large part of the surplus (i.e., when $\gamma$ is high), the issuance of unsolicited ratings leads to less ratings inflation and, thus, improves social welfare by preventing firms from investing in negative NPV projects.

\section{Conclusion}

In this paper, we develop a dynamic rational expectations model to address the question of why credit rating agencies issue unsolicited ratings and why these ratings are, on average, lower than solicited ratings. We analyze the implications of this practice for credit rating standards, rating fees, and social welfare. Our model incorporates three critical elements of the credit rating industry: (i) the rating agencies' ability to misreport the issuer's credit quality, (ii) their ability to issue unsolicited ratings, and (iii) their reputational concerns. We focus on a monopolistic rating agency that interacts with a series of potential issuers. In equilibrium, the agency trades off a higher short-term profit from selling inflated ratings to low-quality issuers against a lower long-term profit associated with a reduction in its reputation. 
Our analysis shows that the rating agency issues unsolicited ratings for two reasons. First, it enables the rating agency to charge higher fees for solicited ratings, because it can credibly threaten to punish issuers that refuse to solicit a rating with an unfavorable unsolicited rating. This increases the value of a favorable rating and, hence, the fee that an issuer is willing to pay for it. Second, by issuing a low unsolicited rating, the rating agency can demonstrate to investors that it resists the temptation to issue inflated ratings, which improves its reputation.

We demonstrate that, in equilibrium, unsolicited ratings are lower than solicited ratings, because all favorable ratings are solicited. This does not mean, however, that unsolicited ratings have a downward bias. Rather, they reflect the lower quality of firms that do not request a rating.

Comparing credit rating systems with and without unsolicited ratings, we find that while rating agencies benefit from having the option to issue unsolicited ratings, such a system can actually lead to less stringent credit rating standards, thereby reducing social welfare. 


\section{Appendix}

Proof of Lemma 1. This result follows immediately from the definition of $V_{t}^{H}$ in equation (3) and the updated probability $\alpha_{t}^{H}$ in equation (2).

Proof of Proposition 1. A type- $G$ firm has no incentive to deviate from its equilibrium strategy by not requesting a rating. Doing so would lower its probability of receiving an $H$-rating to $\delta$, since it would be mistaken for a type- $N$ firm with probability $1-\delta$ by the CRA. As argued in Section 3, a type- $B$ firm also prefers to request a rating: if it requests a rating, it is offered an $H$-rating with probability $p_{t}$; if it does not request a rating, it is offered an $H$-rating only with probability $\delta p_{t}$, since it is mistaken for a type- $N$ firm with probability $1-\delta$ by the CRA. Thus, it is optimal to request a rating for both types of firms as long as $V_{t}^{H}-I-\phi_{t} \geq V_{t}^{\emptyset}$, which is the case in equilibrium.

The investors' valuation of an $H$-rated firm gross of investment expenses, $V_{t}^{H}$, is given by equation (3), which is based on the updated probabilities $\mu_{t}^{H}$ and $\alpha_{t}^{H}$. In equilibrium, the investors' beliefs about the CRA's rating policy have to coincide with its actual policy. Thus, $\tilde{p}_{1}=p_{1}>0$ in equations (1) and (2). The investors' valuation of an unrated firm in

period $1, V_{1}^{\emptyset}$, is given by equation (5), where the updated probability $\beta_{1}^{\emptyset}$ in equation (6) is again based on the equilibrium value $\tilde{p}_{1}=p_{1}>0$; the value of an unrated firm in period $2, V_{2}^{\emptyset}$, is zero. Since firms maximize the (net) market value of their shares, the maximum amount that they are willing to pay for an $H$-rating is therefore given by the difference in valuations, $V_{t}^{H}-I-V_{t}^{\emptyset}>0$, taking into account the investment expenses $I$ of an $H$ rated firm. By assumption, the CRA's rating fee is a fraction $\gamma$ of this surplus value, that is, $\phi_{t}=\gamma\left(V_{t}^{H}-I-V_{t}^{\emptyset}\right)$, which is independent of the firm's type $\theta$. Further, since firms capture a fraction $1-\gamma$ of the surplus, they always acquire an $H$-rating if they are offered one.

Firms never pay for an $L$-rating. This is supported by the off-equilibrium belief that an $L$-rated firm is of type $B$ with probability one, which implies that the investors' valuation of 
such a firm is zero. Thus, firms are better off remaining unrated.

Firms with an $H$-rating can raise sufficient capital to finance the investment project, since $V_{t}^{H} \geq \alpha q R>I, t \in\{1,2\}$. On the other hand, unrated firms are not able to raise the necessary funds, since by doing so, they would reveal to investors that they are of type $B$ and, hence, that their project has a negative NPV.

In period 2, the opportunistic CRA chooses a rating policy $p_{2}^{\theta}, \theta \in\{G, B\}$, to maximize its expected profit, which is given by:

$$
\pi_{2}\left(\mu_{2}\right)=\beta\left(\alpha p_{2}^{G}+(1-\alpha) p_{2}^{B}\right) \phi_{2}
$$

Clearly, since the fee $\phi_{2}$ depends on the investors' beliefs about the CRA's rating policy, rather than its actual policy, this expression is maximized by offering an $H$-rating to all firms that seek financing (i.e., $p_{2}^{G}=p_{2}^{B}=1$ ).

In period 1, the opportunistic CRA maximizes (a generalized version of) the objective function in equation (11):

$$
\begin{aligned}
\pi_{1}= & \alpha \beta\left(p_{1}^{G}\left(\phi_{1}+q \pi_{2}\left(\mu_{1}^{H, S}\right)+(1-q) \pi_{2}\left(\mu_{1}^{H, F}\right)\right)+\left(1-p_{1}^{G}\right) \pi_{2}\left(\mu_{1}^{\emptyset}\right)\right) \\
& +(1-\alpha) \beta\left(p_{1}^{B}\left(\phi_{1}+\pi_{2}\left(\mu_{1}^{H, F}\right)\right)+\left(1-p_{1}^{B}\right) \pi_{2}\left(\mu_{1}^{\emptyset}\right)\right) \\
& +(1-\beta) \pi_{2}\left(\mu_{1}^{\emptyset}\right) .
\end{aligned}
$$

We prove the optimality of the strategy $p_{1}^{G}=1$ and $p_{1}^{B}>0$ by contradiction. First, suppose that $p_{1}^{B}=0$ (and that $p_{1}^{G}>0$ ). Then, only type- $G$ firms receive an $H$-rating, which means that the failure of an $H$-rated firm does not reveal any new information to investors. Thus, $\mu_{1}^{H, F}=\mu_{1}^{H}$. Further, the opportunistic CRA is (weakly) less likely to issue an $H$-rating than the ethical CRA, which implies that $\mu_{1}^{H} \geq \mu_{1}$ and that $\mu_{1}^{\emptyset} \leq \mu_{1}$. Thus, the marginal benefit 
of the opportunistic CRA from issuing an $H$-rating for a type- $B$ firm, which is given by:

$$
\frac{d \pi_{1}}{d p_{1}^{B}}=(1-\alpha) \beta\left(\phi_{1}+\pi_{2}\left(\mu_{1}^{H, F}=\mu_{1}^{H}\right)-\pi_{2}\left(\mu_{1}^{\emptyset}\right)\right)
$$

is strictly positive. This follows from the fact that $\phi_{1}>0$ and that the second-period profit $\pi_{2}$ increases in the CRA's reputation, which implies that $\pi_{2}\left(\mu_{1}^{H, F}=\mu_{1}^{H}\right) \geq \pi_{2}\left(\mu_{1}^{\emptyset}\right)$. The strategy $p_{1}^{B}=0$ can therefore not be optimal for the opportunistic CRA.

Next, suppose that $p_{1}^{G}<1$. The fact that $p_{1}^{B}>0$ implies that the opportunistic CRA (weakly) prefers to offer an $H$-rating to bad firms, that is,

$$
\phi_{1}+\pi_{2}\left(\mu_{1}^{H, F}\right) \geq \pi_{2}\left(\mu_{1}^{\emptyset}\right)
$$

However, since the CRA's reputation is higher when an $H$-rated firm succeeds than when it fails (i.e., $\mu_{1}^{H, S}>\mu_{1}^{H, F}$ ), it follows from the above inequality that:

$$
\phi_{1}+q \pi_{2}\left(\mu_{1}^{H, S}\right)+(1-q) \pi_{2}\left(\mu_{1}^{H, F}\right)>\pi_{2}\left(\mu_{1}^{\emptyset}\right)
$$

This shows that the opportunistic CRA strictly prefers to offer an $H$-rating to a type- $G$ firm, contradicting the assumption that $p_{1}^{G}<1$.

Finally, the uniqueness of $p_{1}^{B}$ follows from the fact that the marginal benefit of the opportunistic CRA from issuing an $H$-rating for a type- $B$ firm, which has to be equal to zero at an interior solution $p_{1}^{B} \in(0,1)$, is a strictly decreasing function of $p_{1}^{B}$ in the interval $[0,1]$ when $\tilde{p}_{1}=p_{1}^{B}$ (which has to be the case in equilibrium). To see this, note that:

$$
\begin{aligned}
\frac{d \pi_{1}}{d p_{1}^{B}} & =(1-\alpha) \beta\left(\phi_{1}+\pi_{2}\left(\mu_{1}^{H, F}\right)-\pi_{2}\left(\mu_{1}^{\emptyset}\right)\right) \\
& =(1-\alpha) \beta \gamma\left(\left(\alpha_{1}^{H}+\beta c\right) q R-I-\left(1-\beta_{1}^{\emptyset}\right) \bar{V}\right)
\end{aligned}
$$

where $\bar{V}=\left(\alpha+(1-\alpha)\left(1-\mu_{1}^{\emptyset}\right)\right) \beta(1-\gamma)\left(V_{2}^{H}-I\right)$ (see equation $\left.(7)\right)$, and the coefficient 
$c$ is given by:

$$
c=\frac{\alpha}{1-(1-\alpha) \mu_{1}^{H, F}}-\frac{\alpha}{1-(1-\alpha) \mu_{1}^{\emptyset}},
$$

where the probabilities $\mu_{1}^{\emptyset}$ and $\mu_{1}^{H, F}$ are defined by equations (4) and (9), respectively. Equations (2) and (6) show that both $\alpha_{1}^{H}$ and $\beta_{1}^{\emptyset}$ are strictly decreasing in $p_{1}^{B}$. From the above definition of $c$ - and the expressions for $\mu_{1}^{\emptyset}$ and $\mu_{1}^{H, F}$ in equations (4) and (9) - it also follows that $c$ is a strictly decreasing function of $p_{1}^{B}$. Further, substituting the expression for $V_{2}^{H}$ from equation (3) into the above expression for $\bar{V}$, we have:

$$
\bar{V}=\beta(1-\gamma)\left(\alpha q R-\left(1-(1-\alpha) \mu_{1}^{\emptyset}\right) I\right)
$$

which shows that $\bar{V}$ is an increasing function of $\mu_{1}^{\emptyset}$ and, hence, of $p_{1}^{B}$. This proves that $d \pi_{1} / d p_{1}^{B}$ is a strictly decreasing function of $p_{1}^{B}$.

Proof of Proposition 2. An interior solution $p_{1} \in(0,1)$ is characterized by the fact that $d \pi_{1} / d p_{1}=0$ at $p_{1}=\tilde{p}_{1}$. Substituting the expression for $\bar{V}$ in equation (A9) into the expression for $d \pi_{1} / d p_{1}$ in equation (A7), we can rewrite this equality as:

$$
\left(\alpha_{1}^{H}-\left(1-\beta_{1}^{\emptyset}\right) \beta(1-\gamma) \alpha+\beta c\right) q R-\left(1-\left(1-\beta_{1}^{\emptyset}\right) \beta(1-\gamma)\left(1-(1-\alpha) \mu_{1}^{\emptyset}\right)\right) I=0,
$$

where the coefficient $c$ is defined in equation (A8). Since the coefficient of $I$ is clearly negative, this equality can only hold if the coefficient of $R$ is strictly positive. This proves that the marginal benefit $d \pi_{1} / d p_{1}$ is an increasing function of the payoff $R$. From the derivative of the above equation with respect to the success probability $q$, which is given by:

$$
\left(\alpha_{1}^{H}-\left(1-\beta_{1}^{\emptyset}\right) \beta(1-\gamma) \alpha+\beta c\right) R+\beta q R \frac{d c}{d q}
$$

it follows that $d \pi_{1} / d p_{1}$ is also increasing in $q$, at least for low values of $q$. (Since $\mu_{1}^{H, F}$ and hence $c$ are decreasing in $q$, this result may not hold for large values of $q$.) Further, from the 
proof of Proposition 1 we know that $d \pi_{1} / d p_{1}$ is a decreasing function of $p_{1}$. Thus, it follows from the Implicit Function Theorem that the equilibrium probability with which the CRA offers an $H$-rating to a type- $B$ firm is increasing in $R$ and increasing in $q$ for low values of $q .{ }^{35}$

Since $V_{2}^{H}>I$, it follows from equation (A7) that the marginal benefit $d \pi_{1} / d p_{1}$ is increasing in $\gamma$, the fraction of the surplus value captured by the CRA. This, together with the fact that $d \pi_{1} / d p_{1}$ is decreasing in $p_{1}$, implies that the equilibrium probability $p_{1}$ is increasing in $\gamma$ as well.

The comparative statics results with respect to the CRA's reputation $\mu_{1}$ follow from the fact that for $\mu_{1}=0$ and $\mu_{1}=1$ no updating of the CRA's reputation takes place. Thus, $\mu_{1}^{H, F}=\mu_{1}^{\emptyset}$ and, consequently, $\pi_{2}\left(\mu_{1}^{H, F}\right)=\pi_{2}\left(\mu_{1}^{\emptyset}\right)$ when $\mu_{1} \in\{0,1\}$, implying that the CRA's marginal benefit in equation (A7) is proportional to the fee $\phi_{1}$, which is strictly positive for all $\tilde{p}_{1} \in[0,1]$. This proves that the equilibrium value of $p_{1}$ converges to one as $\mu_{1}$ goes to either zero or one. The CRA's credit rating standard, $1-p_{1}$, is therefore increasing in $\mu_{1}$ for values of $\mu_{1}$ close to zero, and decreasing in $\mu_{1}$ for values of $\mu_{1}$ close to one.

Proof of Proposition 3. The arguments proving the optimality of the firms' strategies specified in part (i) and the CRA's strategy in part (ii) are identical to those given in the proof of Proposition 1 (and are therefore omitted for brevity), with three exceptions: (i) we need to show that type- $G$ firms prefer to acquire an $H$-rating for a fee of $\hat{\phi}_{t}$ rather than hoping to receive an unsolicited $h$-rating for free; (ii) we have to demonstrate that the opportunistic CRA prefers to issue an unsolicited $\ell$-rating if a firm declines the offer to acquire a solicited rating; and (iii) we have to take into account that type- $B$ firms may be better off not requesting a rating (as argued in Section 4). Further, it is important to note that, compared to the solicited-only rating system, the surplus value of a solicited $H$-rating is greater, since firms that refuse to acquire an $H$-rating receive an unsolicited $\ell$-rating. Thus,

\footnotetext{
${ }^{35}$ Note that this is trivially true in a weak sense for the corner solution $p_{1}=1$.
} 
the surplus value is now given by the difference between the value of an $H$-rated firm net of investment expenses, which is $\hat{V}_{t}^{H}-I$, and the value of an $\ell$-rated firm, which is zero (since, in equilibrium, only type- $B$ firms with negative NPV projects receive such a rating).

As in the solicited-only rating system, type- $B$ firms are better off acquiring an $H$-rating if they are offered one, since otherwise they would receive an unsolicited $\ell$-rating and thus have zero value. Type- $G$ firms, on the other hand, may receive an unsolicited $h$-rating after declining the offer to acquire a solicited $H$-rating if the CRA turns out to be of the ethical type (which happens with probability $\mu_{t}$ ). In this case, the firm's payoff equals $\hat{V}_{t}^{h}-I$, where $\hat{V}_{t}^{h}$ is the off-equilibrium market value of a firm with an unsolicited $h$-rating (which depends on the investors' off-equilibrium beliefs, but can never exceed $q R$ ). Thus, type- $G$ firms prefer to acquire an $H$-rating if their equilibrium payoff, which is $(1-\gamma)\left(\hat{V}_{t}^{H}-I\right)$, exceeds their expected payoff from refusing to do so, which is $\mu_{t}\left(\hat{V}_{t}^{h}-I\right)$. Since $\hat{V}_{t}^{H}>\alpha q R$ and $\hat{V}_{t}^{h} \leq q R$, a sufficient condition for this to be the case is that:

$$
\mu_{t} \leq(1-\gamma)(\alpha q R-I) /(q R-I), \quad t \in\{1,2\}
$$

Further, since $\mu_{2}$ is an increasing function of $\mu_{1}$ and $\mu_{2} \leq \hat{\mu}_{1}^{\ell}<1$ for any interior equilibrium $\hat{p}_{1} \in(0,1)$ (which we will show below to exist), there exists a $\bar{\mu}>0$ such that the condition in (A12) holds for any $\mu_{1}<\bar{\mu}$. This proves that the strategies specified in Proposition 3 can be sustained as an equilibrium if the probability that the CRA is of the ethical type is sufficiently low.

We next show that it is optimal for the opportunistic CRA to issue an unsolicited $\ell$ rating if a firm declines the offer to acquire a solicited rating. This follows from the fact that the CRA's updated reputation after issuing an unsolicited $\ell$-rating, $\hat{\mu}_{1}^{\ell}$, strictly exceeds its reputation when no rating is issued, $\hat{\mu}_{1}^{\emptyset}$, or an unsolicited $h$-rating is issued, $\mu_{1}$ (see equations (13) and (14)). Note that this is true for type- $B$ as well as for type- $G$ firms, since neither type of firm can raise the necessary capital to invest after receiving an unsolicited $\ell$-rating, 
which means that no further updating of the CRA's reputation takes place. This proves that the strategies $\hat{u}_{1}^{G}=\hat{u}_{1}^{B}=1$ are indeed part of the CRA's equilibrium rating policy.

We now turn to characterizing the equilibrium values of $\hat{p}_{1}$ and $\hat{\lambda}_{1}$. An interior solution $\left(\hat{p}_{1}, \hat{\lambda}_{1}\right) \in(0,1)^{2}$ is characterized by two conditions, (i) the condition that the opportunistic CRA is indifferent between issuing a solicited $H$-rating for a type- $B$ firm and not issuing one, and (ii) the condition that a type- $B$ firm is indifferent between requesting a rating and not requesting one. Formally, the pair $\left(\hat{p}_{1}, \hat{\lambda}_{1}\right)$ has to satisfy the conditions $f\left(\hat{p}_{1}, \hat{\lambda}_{1}\right)=0$ and $g\left(\hat{p}_{1}, \hat{\lambda}_{1}\right)=0$, where $f$ is the (normalized) marginal benefit of the opportunistic CRA from offering an $H$-rating to a type- $B$ firm given by:

$$
f\left(\hat{p}_{1}, \hat{\lambda}_{1}\right)=\frac{1}{\gamma}\left(\hat{\phi}_{1}+\hat{\pi}_{2}\left(\hat{\mu}_{1}^{H, F}\right)-\hat{\pi}_{2}\left(\hat{\mu}_{1}^{\ell}\right)\right)
$$

and $g$ is the (normalized) marginal benefit of a type- $B$ firm from requesting a rating given by:

$$
g\left(\hat{p}_{1}, \hat{\lambda}_{1}\right)=\frac{1}{1-\gamma}\left(\left(1-\mu_{1}\right) \hat{p}_{1}\left(\hat{V}_{1}^{H}-I-\hat{\phi}_{1}\right)-\hat{V}_{1}^{\emptyset}\right)
$$

where $\hat{V}_{1}^{H}=\hat{\alpha}_{1}^{H} q R$ and $\hat{V}_{1}^{\emptyset}$ is defined by equation (16). The expression for $f$ is similar to the one derived in the proof of Proposition 1 , where $\mu_{1}^{\emptyset}$ is replaced by $\hat{\mu}_{1}^{\ell}$. The expression for $g$ follows from the fact that, by requesting a rating, a type- $B$ firm gives up its option to remain unrated (and, hence, to have a market value of $\hat{V}_{1}^{\emptyset}$ ) in favor of potentially receiving an $H$-rating from an opportunistic CRA (with probability $\hat{p}_{1}$ ), in which case its net market value is $\hat{V}_{1}^{H}-I-\hat{\phi}_{1}$ (in all other cases, it receives an $\ell$-rating and has a market value of zero). Of course, this is only relevant if the CRA does not observe a signal revealing the firm's type. If the CRA observes such a signal, the firm's value is the same whether it requests a rating or not.

In addition, there may also exist corner solutions. These solutions can be defined in terms of the functions $f$ and $g$ as follows: $\hat{p}_{1}=1$ is an equilibrium if $f\left(1, \hat{\lambda}_{1}\right) \geq 0$ (recall 
from the proof of Proposition 1 that $\hat{p}_{1}=0$ cannot be an equilibrium); similarly, $\hat{\lambda}_{1}=0$ is an equilibrium if $g\left(\hat{p}_{1}, 0\right) \leq 0$, and $\hat{\lambda}_{1}=1$ is an equilibrium if $g\left(\hat{p}_{1}, 1\right) \geq 0$.

We proceed by first proving the existence of a pair $\left(\hat{p}_{1}, \hat{\lambda}_{1}\right)$ that satisfies the above equilibrium conditions, and then derive sufficient conditions for it to be the unique (interior) equilibrium. Substituting the expressions for the firm valuations and rating fees derived in Section 4 into the above expressions for $f$ and $g$ yields:

$$
\begin{aligned}
f\left(\hat{p}_{1}, \hat{\lambda}_{1}\right)= & \hat{V}_{1}^{H}-I+\beta\left(\hat{V}_{2}^{H}\left(\hat{\mu}_{1}^{H, F}\right)-I\right)-\beta\left(\hat{V}_{2}^{H}\left(\hat{\mu}_{1}^{\ell}\right)-I\right) \\
= & \left(\hat{\alpha}_{1}^{H}+\frac{\alpha \beta}{1-(1-\alpha) \hat{\mu}_{1}^{H, F}}-\frac{\alpha \beta}{1-(1-\alpha) \hat{\mu}_{1}^{\ell}}\right) q R-I \\
g\left(\hat{p}_{1}, \hat{\lambda}_{1}\right)= & \left(1-\mu_{1}\right) \hat{p}_{1}\left(\hat{V}_{1}^{H}-I\right)-\left(1-\hat{\beta}_{1}^{\emptyset}\right)\left(1-(1-\alpha) \hat{\mu}_{1}^{\emptyset}\right) \beta\left(\hat{V}_{2}^{H}\left(\hat{\mu}_{1}^{\emptyset}\right)-I\right) \\
= & \left(1-\mu_{1}\right) \hat{p}_{1}\left(\hat{\alpha}_{1}^{H} q R-I\right) \\
& -\frac{\beta(1-\beta)}{1-\beta+(1-\alpha) \beta\left(1-\hat{\lambda}_{1}\right)(1-\delta)}\left(\alpha q R-\left(1-(1-\alpha) \mu_{1}\right) I\right),
\end{aligned}
$$

where we have used the fact that, in equilibrium, $\tilde{u}_{1}^{B}=1, \hat{\mu}_{1}^{\emptyset}=\mu_{1}$, and:

$$
\begin{aligned}
\hat{\alpha}_{1}^{H} & =\frac{\alpha}{\mu_{1} \alpha+\left(1-\mu_{1}\right)\left(\alpha+(1-\alpha)\left(\hat{\lambda}_{1}+\left(1-\hat{\lambda}_{1}\right) \delta\right) \hat{p}_{1}\right)} \\
\hat{\mu}_{1}^{H, F} & =\frac{\mu_{1} \alpha(1-q)}{\mu_{1} \alpha(1-q)+\left(1-\mu_{1}\right)\left(\alpha(1-q)+(1-\alpha)\left(\hat{\lambda}_{1}+\left(1-\hat{\lambda}_{1}\right) \delta\right) \hat{p}_{1}\right)}, \\
\hat{\mu}_{1}^{\ell} & =\frac{\mu_{1}}{\mu_{1}+\left(1-\mu_{1}\right)\left(1-\hat{p}_{1}\right)} .
\end{aligned}
$$

From equation (A16), it follows immediately that, for any $\hat{\lambda}_{1} \in[0,1], f\left(\hat{p}_{1}, \hat{\lambda}_{1}\right)$ is a continuous and strictly decreasing function of $\hat{p}_{1}$ in $\mathbb{R}_{+}$with $f\left(0, \hat{\lambda}_{1}\right)=q R-I>0$ and $\lim _{\hat{p}_{1} \rightarrow \infty} f\left(\hat{p}_{1}, \hat{\lambda}_{1}\right)=-I<0$. Thus, for any $\hat{\lambda}_{1} \in[0,1]$, there exists a unique $\hat{p}_{1}\left(\hat{\lambda}_{1}\right) \in \mathbb{R}_{+}$ such that $f\left(\hat{p}_{1}\left(\hat{\lambda}_{1}\right), \hat{\lambda}_{1}\right)=0$. Let $p_{1}^{*}\left(\hat{\lambda}_{1}\right)=\min \left\{\hat{p}_{1}\left(\hat{\lambda}_{1}\right), 1\right\}$ and note that $p_{1}^{*}\left(\hat{\lambda}_{1}\right)$ is a continuous and (weakly) decreasing function of $\hat{\lambda}_{1}$ in the interval $[0,1]$. This follows from the Implicit 
Function Theorem since $\frac{\partial f}{\partial \hat{p}_{1}}<0$ and $\frac{\partial f}{\partial \hat{\lambda}_{1}}<0$ for all $\hat{p}_{1}, \hat{\lambda}_{1} \in[0,1]$.

Similarly, from equation (A18), it follows that, for any $\hat{p}_{1} \in[0,1], g\left(\hat{p}_{1}, \hat{\lambda}_{1}\right)$ is a continuous and strictly decreasing function of $\hat{\lambda}_{1}$ in $\mathbb{R}_{+}$. Thus, for any $\hat{p}_{1} \in[0,1]$, there exists at most one $\hat{\lambda}_{1}\left(\hat{p}_{1}\right) \in[0,1]$ such that $g\left(\hat{p}_{1}, \hat{\lambda}_{1}\left(\hat{p}_{1}\right)\right)=0$. Let $\lambda_{1}^{*}\left(\hat{p}_{1}\right)=\hat{\lambda}_{1}\left(\hat{p}_{1}\right)$ if such a $\hat{\lambda}_{1}\left(\hat{p}_{1}\right) \in[0,1]$ exists. If such a $\hat{\lambda}_{1}\left(\hat{p}_{1}\right)$ does not exist, either $g\left(\hat{p}_{1}, 1\right)>0$, in which case let $\lambda_{1}^{*}\left(\hat{p}_{1}\right)=1$, or $g\left(\hat{p}_{1}, 0\right)<0$, in which case let $\lambda_{1}^{*}\left(\hat{p}_{1}\right)=0$.

Using the above definitions of $p_{1}^{*}\left(\hat{\lambda}_{1}\right)$ and $\lambda_{1}^{*}\left(\hat{p}_{1}\right)$, a strategy pair $\left(\hat{p}_{1}, \hat{\lambda}_{1}\right)$ is an equilibrium if $\hat{p}_{1}=p_{1}^{*}\left(\hat{\lambda}_{1}\right)$ and $\hat{\lambda}_{1}=\lambda_{1}^{*}\left(\hat{p}_{1}\right)$. Note that this definition encompasses interior solutions as well as corner solutions. To prove the existence of such a fixed point, it suffices to show that there exists a $\hat{\lambda}_{1} \in[0,1]$ such that $\lambda_{1}^{*}\left(p_{1}^{*}\left(\hat{\lambda}_{1}\right)\right)=\hat{\lambda}_{1}$. The existence of such a $\hat{\lambda}_{1}$ follows from Brouwer's fixed point theorem, since $\lambda_{1}^{*}\left(p_{1}^{*}\left(\hat{\lambda}_{1}\right)\right)$ is a continuous function from $[0,1]$ to $[0,1]$. This, together with the arguments given in the proof of Proposition 1, prove the existence of a pair $\left(\hat{p}_{1}, \hat{\lambda}_{1}\right)$ such that the strategies specified in the proposition constitute an equilibrium.

To prove the uniqueness of the strategy pair $\left(\hat{p}_{1}, \hat{\lambda}_{1}\right)$ if $I \leq \alpha^{2} q R$, it suffices to show that this condition ensures that $\lambda_{1}^{*}\left(p_{1}^{*}\left(\hat{\lambda}_{1}\right)\right)$ is decreasing in $\hat{\lambda}_{1}$, or equivalently that $\lambda_{1}^{*}\left(\hat{p}_{1}\right)$ is increasing in $\hat{p}_{1}$ (recall that $p_{1}^{*}\left(\hat{\lambda}_{1}\right)$ is decreasing in $\left.\hat{\lambda}_{1}\right)$. From the Implicit Function Theorem, it follows that $\hat{\lambda}_{1}\left(\hat{p}_{1}\right)$, and hence $\lambda_{1}^{*}\left(\hat{p}_{1}\right)$, is increasing in $\hat{p}_{1}$ if $\frac{\partial g}{\partial \hat{\lambda}_{1}}<0$, which we established above, and $\frac{\partial g}{\partial \hat{p}_{1}}>0$. From equation (A18), we have:

$$
\frac{\partial g}{\partial \hat{p}_{1}}=\left(1-\mu_{1}\right)\left(\left(\hat{\alpha}_{1}^{H}+\hat{p}_{1} \frac{d \hat{\alpha}_{1}^{H}}{d \hat{p}_{1}}\right) q R-I\right)=\left(1-\mu_{1}\right)\left(\left(\hat{\alpha}_{1}^{H}\right)^{2} q R-I\right) .
$$

Since $\hat{\alpha}_{1}^{H} \geq \alpha$, the above expression is strictly positive if $I<\alpha^{2} q R$.

We conclude the proof by noting that a sufficient condition for the existence of an interior equilibrium $\hat{p}_{1}<1$ is that $f(1,1)<0$ and $g(1,1)>0$, where $f$ and $g$ are defined in equations (A13) and (A14), respectively. By direct inspection of (A13) and (A14), it is straightforward to show that, for low enough values of $\mu_{1}$, we have that $g(1,1)>0$ as long as the average investment project has a positive NPV (i.e., as long as $\alpha q R>I$, which we assumed at the 
outset) and that $f(1,1)<0$ if $\beta>\alpha /(1-\alpha)$.

Proof of Corollary 1. This result follows immediately from Proposition 3.

Proof of Proposition 4. From the proof of Proposition 3, we know that an interior solution $\left(\hat{p}_{1}, \hat{\lambda}_{1}\right) \in(0,1)^{2}$ has to satisfy the conditions $f\left(\hat{p}_{1}, \hat{\lambda}_{1}\right)=0$ and $g\left(\hat{p}_{1}, \hat{\lambda}_{1}\right)=0$, where $f$ and $g$ are defined in equations (A13) and (A14), respectively. Applying the Implicit Function Theorem (and Cramer's rule) to this system of equations lets us compute the derivative of $\hat{p}_{1}$ with respect to $R$ as:

$$
\frac{d \hat{p}_{1}}{d R}=-\frac{\left|\begin{array}{ll}
\frac{\partial f}{\partial R} & \frac{\partial f}{\partial \hat{\lambda}_{1}} \\
\frac{\partial g}{\partial R} & \frac{\partial g}{\partial \hat{\lambda}_{1}}
\end{array}\right|}{\left|\begin{array}{cc}
\frac{\partial f}{\partial \hat{p}_{1}} & \frac{\partial f}{\partial \hat{\lambda}_{1}} \\
\frac{\partial g}{\partial \hat{p}_{1}} & \frac{\partial g}{\partial \hat{\lambda}_{1}}
\end{array}\right|}
$$

In the proof of Proposition 3, we have already shown that $\frac{\partial f}{\partial \hat{\lambda}_{1}}<0, \frac{\partial f}{\partial \hat{p}_{1}}<0$, and $\frac{\partial g}{\partial \hat{\lambda}_{1}}<0$. If $I<\alpha^{2} q R$, we also have that $\frac{\partial g}{\partial \hat{p}_{1}}>0$. Thus, to prove that $\frac{d \hat{p}_{1}}{d R}>0$, it suffices to show that $\frac{\partial f}{\partial R}>0$ and $\frac{\partial g}{\partial R}<0$.

The result that $\frac{\partial f}{\partial R}>0$ follows immediately from equation (A16): since the coefficient of $I$ is negative, the equilibrium condition $f\left(\hat{p}_{1}, \hat{\lambda}_{1}\right)=0$ can only hold if the coefficient of $R$ is strictly positive.

To see that $\frac{\partial g}{\partial R}<0$, note that equation (A17) can be written as:

$$
g\left(\hat{p}_{1}, \hat{\lambda}_{1}\right)=\left(1-\mu_{1}\right) \hat{p}_{1}\left(\hat{\alpha}_{1}^{H} q R-I\right)-\left(1-\hat{\beta}_{1}^{\emptyset}\right)\left(1-(1-\alpha) \hat{\mu}_{1}^{\emptyset}\right) \beta\left(\hat{\alpha}_{2}^{H}\left(\hat{\mu}_{1}^{\emptyset}\right) q R-I\right) .
$$

Since in equilibrium $\tilde{u}_{1}^{B}=1$, we have $\hat{\mu}_{1}^{\emptyset}=\mu_{1}$. This, together with the fact that $\left(\hat{\lambda}_{1}+\left(1-\hat{\lambda}_{1}\right) \delta\right) \hat{p}_{1}<$ $1=\left(\hat{\lambda}_{2}+\left(1-\hat{\lambda}_{2}\right) \delta\right) \hat{p}_{2}$, implies that $\hat{\alpha}_{1}^{H}>\hat{\alpha}_{2}^{H}\left(\hat{\mu}_{1}^{\emptyset}\right)$. Thus, the equilibrium condition $g\left(\hat{p}_{1}, \hat{\lambda}_{1}\right)=0$ can only hold if $\left(1-\mu_{1}\right) \hat{p}_{1}<\left(1-\hat{\beta}_{1}^{\emptyset}\right)\left(1-(1-\alpha) \hat{\mu}_{1}^{\emptyset}\right) \beta$. This, however, means that the coefficient of $I$ in equation (A24) is positive. Hence, the coefficient of $R$ must be negative for an interior equilibrium to exist, proving that $\frac{\partial g}{\partial R}<0$. 
Since the coefficient of $R$ in equation (A24) is proportional to $q$, the above argument shows that $\frac{\partial g}{\partial q}<0$ as well. Further, since the coefficient of $R$ in equation (A16) can be written as $d(q) q>0$, it follows that, for low values of $q, \frac{\partial f}{\partial q}>0$. (Since $\mu_{1}^{H, F}$ and hence $d(q)$ are decreasing in $q$, this result may not hold for large values of $q$.) Thus, the arguments made above show that $\frac{d \hat{p}_{1}}{d q}>0$ as well, at least for low values of $q$.

The result that the equilibrium probability $\hat{p}_{1}$ is independent of $\gamma$ follows immediately from the fact that neither $f$ nor $g$ is a function of $\gamma$.

Finally, analogous arguments to those made in the proof of Proposition 2 (where $\mu_{1}^{\emptyset}$ has to be replaced by $\hat{\mu}_{1}^{\ell}$ ) show that the rating standard, $1-p_{1}$, increases in $\mu_{1}$ for values of $\mu_{1}$ close to zero, and decreases in $\mu_{1}$ for values of $\mu_{1}$ close to one.

Proof of Proposition 5. We prove this result by first showing that, for $\gamma=1, \hat{\phi}_{1}$ exceeds $\phi_{1}$. We then show that the "normalized" fee $\phi_{1} / \gamma$ is increasing in $\gamma$ for all $\gamma \in(0,1]$, whereas $\hat{\phi}_{1} / \gamma$ does not depend on $\gamma$. This implies that $\hat{\phi}_{1}$ exceeds $\phi_{1}$ for all $\gamma \in(0,1]$.

In the solicited-only credit rating system, the fee charged for an $H$-rating in the first period is:

$$
\phi_{1}=\gamma\left(V_{1}^{H}-I-V_{1}^{\emptyset}\right)=\gamma\left(\alpha_{1}^{H} q R-I-\left(1-\beta_{1}^{\emptyset}\right) \bar{V}\right)
$$

whereas in the credit rating system with unsolicited ratings, the fee is:

$$
\hat{\phi}_{1}=\gamma\left(\hat{V}_{1}^{H}-I\right)=\gamma\left(\hat{\alpha}_{1}^{H} q R-I\right)
$$

If $\gamma=1, \bar{V}$ is equal to zero. Thus, $\hat{\phi}_{1}>\phi_{1}$ if and only if $\hat{\alpha}_{1}^{H}>\alpha_{1}^{H}$. From the updated probabilities in equations (1), (2), and (A19), it follows that this is the case if $\left(\hat{\lambda}_{1}+(1-\right.$ $\left.\left.\hat{\lambda}_{1}\right) \delta\right) \hat{p}_{1}<p_{1}$. As argued in the proofs of Propositions 1 and 3 , in equilibrium the two quantities $p_{1}$ and $\left(\hat{\lambda}_{1}+\left(1-\hat{\lambda}_{1}\right) \delta\right) \hat{p}_{1}$ have to satisfy the following constraints (assuming an 
interior solution):

$$
\begin{aligned}
\phi_{1}+\pi_{2}\left(\mu_{1}^{H, F}\right)-\pi_{2}\left(\mu_{1}^{\emptyset}\right) & =0, \\
\hat{\phi}_{1}+\hat{\pi}_{2}\left(\hat{\mu}_{1}^{H, F}\right)-\hat{\pi}_{2}\left(\hat{\mu}_{1}^{\ell}\right) & =0 .
\end{aligned}
$$

If $p_{1}=\left(\hat{\lambda}_{1}+\left(1-\hat{\lambda}_{1}\right) \delta\right) \hat{p}_{1}$, it follows immediately that $\phi_{1}=\hat{\phi}_{1}$ and $\pi_{2}\left(\mu_{1}^{H, F}\right)=\hat{\pi}_{2}\left(\hat{\mu}_{1}^{H, F}\right)$. Further, the expressions for $\mu_{1}^{\emptyset}$ and $\hat{\mu}_{1}^{\ell}$ in equations (4) and (13) imply that $\mu_{1}^{\emptyset}<\hat{\mu}_{1}^{\ell}$ and, thus, that $\pi_{2}\left(\mu_{1}^{\emptyset}\right)<\hat{\pi}_{2}\left(\hat{\mu}_{1}^{\ell}\right)$. Hence, for $p_{1}=\left(\hat{\lambda}_{1}+\left(1-\hat{\lambda}_{1}\right) \delta\right) \hat{p}_{1}$, the marginal benefit of issuing an $H$-rating for a type- $B$ firm in the solicited-only case (given by equation (A27)) exceeds that in the case with unsolicited ratings (given by equation (A28)). Combined with the fact that the expressions in equations (A27) and (A28) are decreasing functions of $p_{1}$ and $\left(\hat{\lambda}_{1}+\left(1-\hat{\lambda}_{1}\right) \delta\right) \hat{p}_{1}$, respectively (see the proofs of Propositions 1 and 3 ), this implies that $p_{1}>\left(\hat{\lambda}_{1}+\left(1-\hat{\lambda}_{1}\right) \delta\right) \hat{p}_{1}$. Thus, $\hat{\phi}_{1}>\phi_{1}$ when $\gamma=1$.

The proof of Proposition 3 shows that the equilibrium values of $\hat{p}_{1}$ and $\hat{\lambda}_{1}$, and hence the (normalized) fee $\hat{\phi}_{1} / \gamma$, do not depend on $\gamma$. In contrast, equation (A25) shows that, for a fixed $p_{1}$, an increase in $\gamma$ leads to an increase in the (normalized) fee $\phi_{1} / \gamma$ through its effect on $\bar{V}$ (equation (A9)). Of course, this change in the fee also leads to a change in $p_{1}$. According to the equilibrium condition in (A27), we have:

$$
\frac{d\left(\phi_{1} / \gamma\right)}{d \gamma}=-\frac{d}{d \gamma}\left(\pi_{2}\left(\mu_{1}^{H, F}\right) / \gamma-\pi_{2}\left(\mu_{1}^{\emptyset}\right) / \gamma\right)=-\frac{\partial}{\partial p_{1}}\left(\pi_{2}\left(\mu_{1}^{H, F}\right) / \gamma-\pi_{2}\left(\mu_{1}^{\emptyset}\right) / \gamma\right) \frac{d p_{1}}{d \gamma}
$$

where the second equality follows from the fact that, for a given $p_{1}$, the (normalized) profit $\pi_{2} / \gamma$ is independent of $\gamma$ (i.e., $\pi_{2} / \gamma$ depends on $\gamma$ only through $p_{1}$ ). Since the (normalized) fee $\phi_{1} / \gamma$ is increasing in $\gamma$ and since the marginal benefit in equation (A27) is strictly decreasing in $p_{1}$ (see the proof of Proposition 1), it follows from the Implicit Function Theorem that $\frac{d p_{1}}{d \gamma}>0$. Further, since $\mu_{1}^{H, F}$ is decreasing in $p_{1}$ and $\mu_{1}^{\emptyset}$ is increasing in $p_{1}$, it follows that $\pi_{2}\left(\mu_{1}^{H, F}\right) / \gamma-\pi_{2}\left(\mu_{1}^{\emptyset}\right) / \gamma$ is decreasing in $p_{1}$. This proves that the (normalized) fee $\phi_{1} / \gamma$ is an 
increasing function of $\gamma$, taking into account the indirect effect of $\gamma$ on the equilibrium value of $p_{1}$. Thus, $\hat{\phi}_{1}$ exceeds $\phi_{1}$ for all $\gamma \in(0,1]$.

Proof of Proposition 6. In the proof of Proposition 5, we have already shown that $p_{1}>$ $\left(\hat{\lambda}_{1}+\left(1-\hat{\lambda}_{1}\right) \delta\right) \hat{p}_{1}$ if $\gamma=1$. If $\gamma$ is close to its lower bound of zero (but strictly positive), this result can be reversed. In this case, $\bar{V}$ is large. Thus, for a given level of reputation, the fee that the CRA can charge for an $H$-rating in the first period is lower in the solicited-only rating system than in the system with unsolicited ratings (i.e., $\left.\phi_{1}<\hat{\phi}_{1}\right)$ when $p_{1}=\left(\hat{\lambda}_{1}+\left(1-\hat{\lambda}_{1}\right) \delta\right) \hat{p}_{1}$. This is true even for values of $\alpha$ close to one:

$$
\lim _{\alpha \rightarrow 1} \hat{\phi}_{1}-\phi_{1}=\lim _{\alpha \rightarrow 1} \gamma\left(1-\beta_{1}^{\emptyset}\right) \bar{V}=\gamma(1-\gamma) \beta(q R-I)>0
$$

In contrast, the difference between the second-period profits in the two cases converges to zero as $\alpha$ goes to one, since $\pi_{2}\left(\mu_{1}^{H, F}\right)=\hat{\pi}_{2}\left(\hat{\mu}_{1}^{H, F}\right)$ when $p_{1}=\left(\hat{\lambda}_{1}+\left(1-\hat{\lambda}_{1}\right) \delta\right) \hat{p}_{1}$ and:

$$
\lim _{\alpha \rightarrow 1} \hat{\pi}_{2}\left(\hat{\mu}_{1}^{\ell}\right)-\pi_{2}\left(\mu_{1}^{\emptyset}\right)=\lim _{\alpha \rightarrow 1} \beta \gamma\left(\frac{\alpha}{1-(1-\alpha) \hat{\mu}_{1}^{\ell}}-\frac{\alpha}{1-(1-\alpha) \mu_{1}^{\emptyset}}\right) q R=0
$$

This result follows immediately from from equations (2) and (3). Thus, if $\alpha$ is sufficiently large, the marginal benefit from offering an $H$-rating to a type- $B$ firm in the case with unsolicited ratings, $d \hat{\pi}_{1} / d \hat{p}_{1}$, exceeds the marginal benefit in the solicited-only case, $d \pi_{1} / d p_{1}$, for all $p_{1}=\left(\hat{\lambda}_{1}+\left(1-\hat{\lambda}_{1}\right) \delta\right) \hat{p}_{1}$. From the fact that $d \pi_{1} / d p_{1}$ and $d \hat{\pi}_{1} / d \hat{p}_{1}$ are decreasing functions of $p_{1}$ and $\left(\hat{\lambda}_{1}+\left(1-\hat{\lambda}_{1}\right) \delta\right) \hat{p}_{1}$, respectively (see the proofs of Propositions 1 and 3 ), it then follows that $p_{1}<\left(\hat{\lambda}_{1}+\left(1-\hat{\lambda}_{1}\right) \delta\right) \hat{p}_{1}$. This proves that there exist parameter values such that the extent of ratings inflation is greater in the credit rating system with unsolicited ratings.

Proof of Proposition 7. If the social welfare function is equally weighted, social welfare is lower the more type- $B$ firms obtain an $H$-rating and invest in their negative NPV projects. 
Thus, social welfare is directly related to the extent of ratings inflation in our model. The result in Proposition 7 therefore follows immediately from Proposition 6. 


\section{References}

Ashcraft, A., P. Goldsmith-Pinkham, and J. Vickery, 2010, "MBS Ratings and the Mortgage Credit Boom," Working Paper, Federal Reserve Bank of New York.

Avramov, D., T. Chordia, G. Jostova, and A. Philipov, 2012, "Anomalies and Financial Distress," Journal of Financial Economics, forthcoming.

Banerjee, A. V., and E. Duflo, 2000, "Reputation Effects and the Limits of Contracting: A Study of the Indian Software Industry," Quarterly Journal of Economics, 115, 989-1017.

Bannier, C. E., P. Behr, and A. Güttler, 2010, "Rating Opaque Borrowers: Why Are Unsolicited Ratings Lower?," Review of Finance, 14, 263-294.

Bolton, P., X. Freixas, and J. Shapiro, 2012, "The Credit Ratings Game," Journal of Finance, $67,85-112$.

Cabral, L. M. B., 2000, "Stretching Firm and Brand Reputation," RAND Journal of Economics, 31, 658-673.

Chemmanur, T. J., and P. Fulghieri, 1994a, "Investment Bank Reputation, Information Production, and Financial Intermediation," Journal of Finance, 49, 57-59.

Chemmanur, T. J., and P. Fulghieri, 1994b, "Reputation, Renegotiation, and the Choice between Bank Loans and Publicly Traded Debt," Review of Financial Studies, 7, 475-506.

Diamond, D. W., 1989, "Reputation Acquisition in Debt Markets," Journal of Political Economy, $97,828-862$.

Faulkender, M., and M. A. Petersen, 2006, "Does the Source of Capital Affect Capital Structure?," Review of Financial Studies, 19, 45-79.

Fisher, A., and R. Heinkel, 2008, "Reputation and Managerial Truth-Telling as SelfInsurance," Journal of Economics and Management Strategy, 17, 489-540.

Gan, Y. H., 2004, "Why Do Firms Pay for Bond Ratings When They Can Get Them for Free?," Working Paper, University of Pennsylvania.

He, J., J. Qian, and P. E. Strahan, 2012, "Are All Ratings Created Equal? The Impact of Issuer Size on the Pricing of Mortgage-Backed Securities," Journal of Finance, forthcoming.

Hörner, J., 2002, "Reputation and Competition," American Economic Review, 92, 644-663. 
Klein, A., 2004, "Credit Raters' Power Leads to Abuses, Some Borrowers Say," The Washington Post, November 24, 2004.

Kreps, D. M., and R. Wilson, 1982, "Reputation and Imperfect Information," Journal of Economic Theory, 27, 253-279.

Langohr, H. M., and P. T. Langohr, 2008, The Rating Agencies and Their Credit Raings: What They Are, How They Work, and Why They Are Relevant, John Wiley \& Sons, New York.

Mailath, G. J., and L. Samuelson, 2006, Repeated Games and Reputations, Oxford University Press, Oxford, United Kingdom.

Mathis, J., J. McAndrews, and J.-C. Rochet, 2009, "Rating the Raters: Are Reputation Concerns Powerful Enough to Discipline Rating Agencies?," Journal of Monetary Economics, $56,657-674$.

Milgrom, P., and J. Roberts, 1982, "Predation, Reputation, and Entry Deterrence," Journal of Economic Theory, 27, 280-312.

Monroe, A., 1987, "Invited or Not, Moody's Begins Rating Securities Backed by Assets, Mortages," The Wall Street Jounal, December 22, 1987.

Moody's, 2011, Policy for Designating Unsolicited Credit Ratings in the European Union, http://www.moodys.com/sites/products/ProductAttachments/Compliance/9-92011/SP13360 Policy for Designating Unsolicited Credit Ratings in the European Union_Sept_06_2011 Final.pdf.

Moody's, 2012, How to Get Rated, http://www.moodys.com/ratings-process/How-to-GetRated/002001.

Opp, C. C., M. M. Opp, and M. Harris, 2012, "Rating Agencies in the Face of Regulation: Rating Inflation and Regulatory Arbitrage," Journal of Financial Economics, forthcoming.

Poon, W. P. H., 2003, "Are Unsolicited Credit Ratings Biased Downward?," Jounal of Banking and Finance, 27, 593-614.

Poon, W. P. H., and M. Firth, 2005, "Are Unsolicited Credit Ratings Lower? International Evidence from Bank Ratings," Jounal of Business Finance and Accounting, 32, 1741-1771.

Sangiorgi, F., and C. Spatt, 2011, "Opacity, Credit Rating Shopping and Bias," Working Paper, Stockholm School of Economics and Carnegie Mellon University. 
Schultz, A., 1993, "Divergent Ratings of Fremont Bonds Underscore How the Old Guideposts Aren't Always Clear," The Wall Street Jounal, November 9, 1993.

Skreta, V., and L. Veldkamp, 2009, "Ratings Shopping and Asset Complexity: A Theory of Ratings Inflation," Journal of Monetary Economics, 56, 678-695.

Spatt, C., 2005, Speech by SEC Staff: Regulatory Issues and Economic Principles, http://www.sec.gov/news/speech/spch040105css.htm.

Standard \& Poor's, 2007, Unsolicited Ratings, Policy Statement, June 26, 2007, http://www2.standardandpoors.com/spf/pdf/fixedincome/unsolicited_ratings_policy.06.26.07.pdf.

Standard \& Poor's, 2012, About Credit Ratings, http://www.standardandpoors.com/aboutcreditratings/RatingsManual_PrintGuide.html.

Tadelis, S., 1999, "What's in a Name? Reputation as a Tradeable Asset," American Economic Review, 89, 548-563.

Van Roy, P., 2006, "Is There a Difference Between Solicited and Unsolicited Bank Ratings and, If So, Why?," Working Paper, National Bank of Belgium.

White, L. J., 2010, "The Credit Rating Agencies," Journal of Economic Perspectives, 24, $211-226$. 


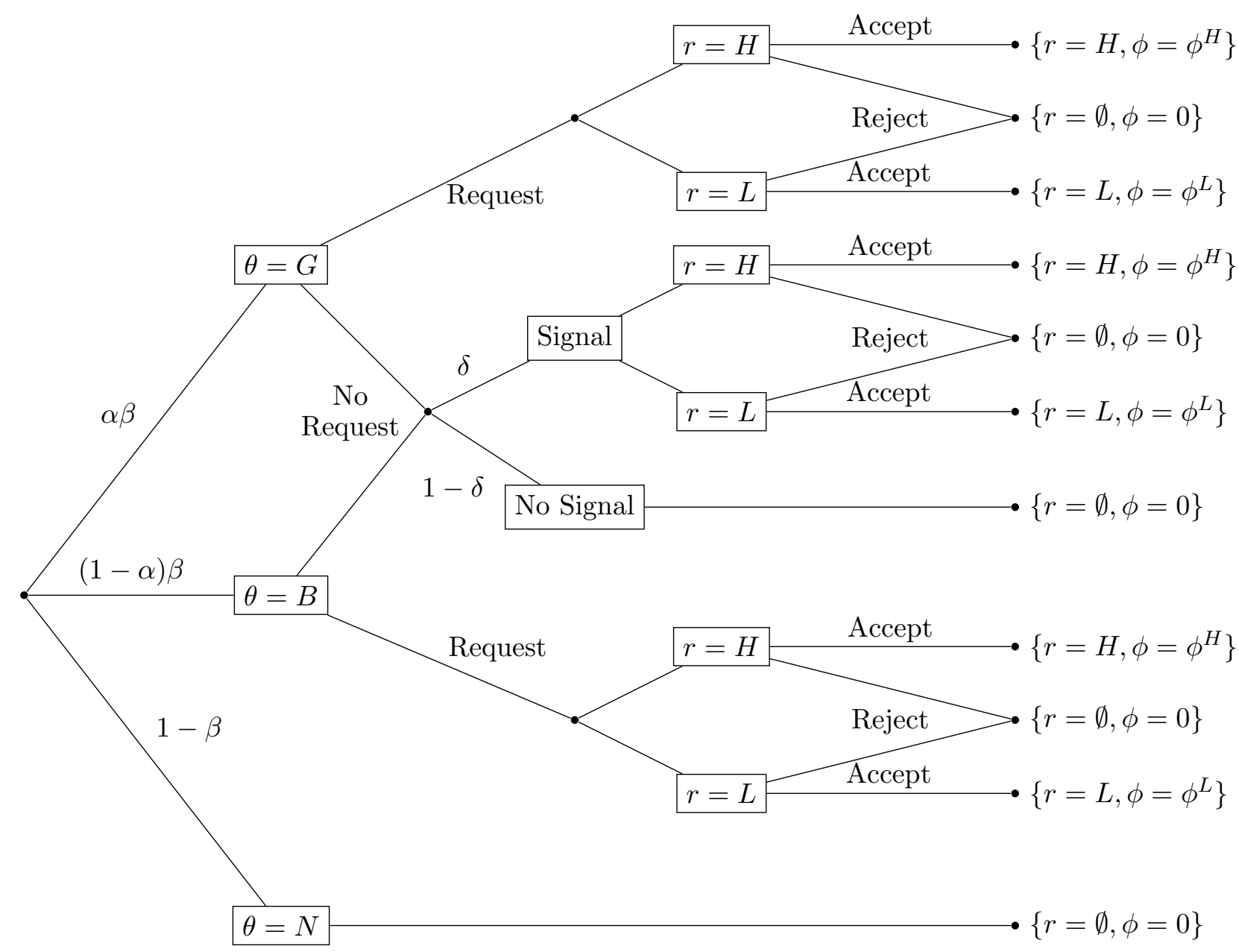

Figure 1: Game Tree of the Solicited-Only Credit Rating System 


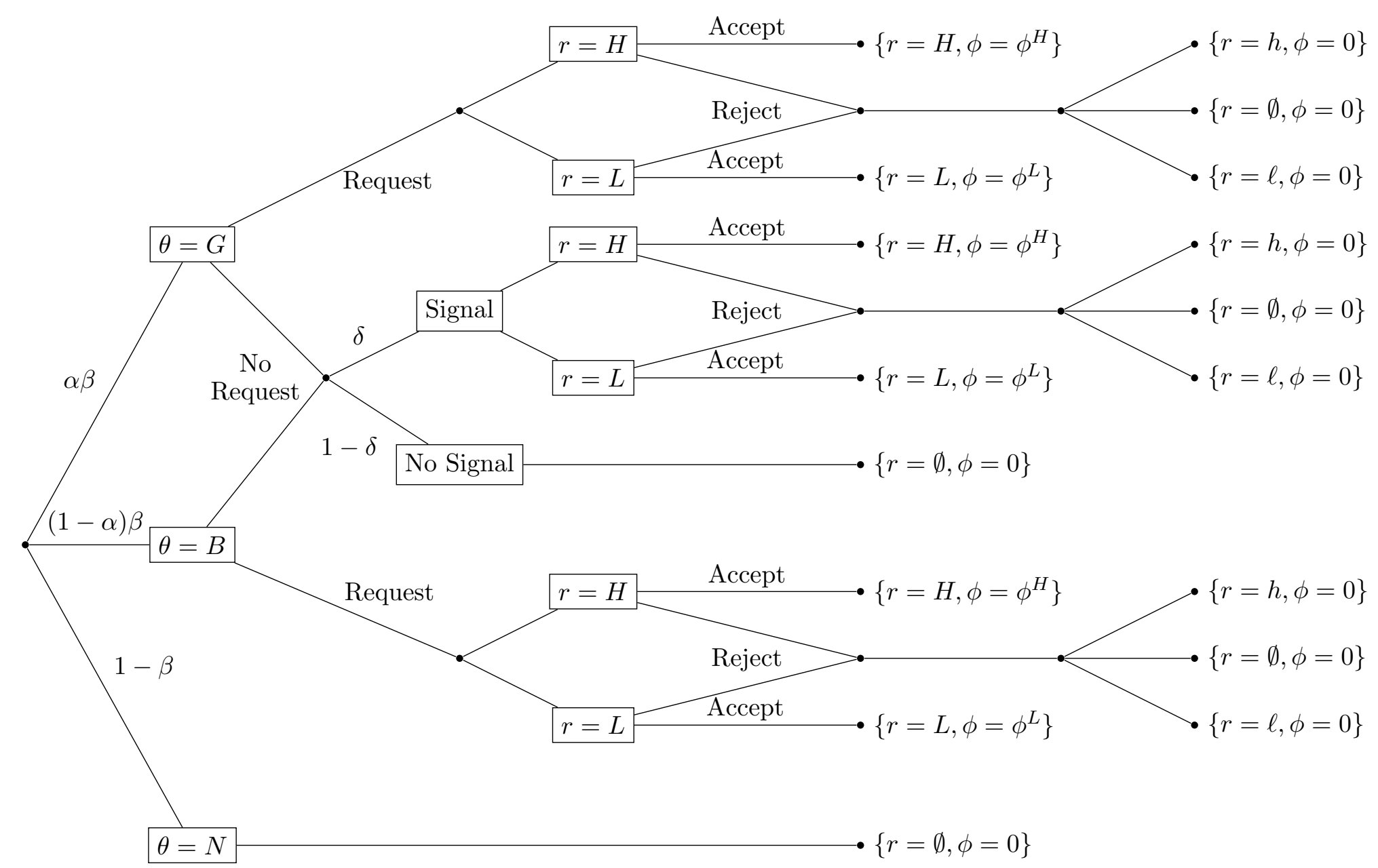

Figure 2: Game Tree of the Credit Rating System with Unsolicited Credit Ratings 